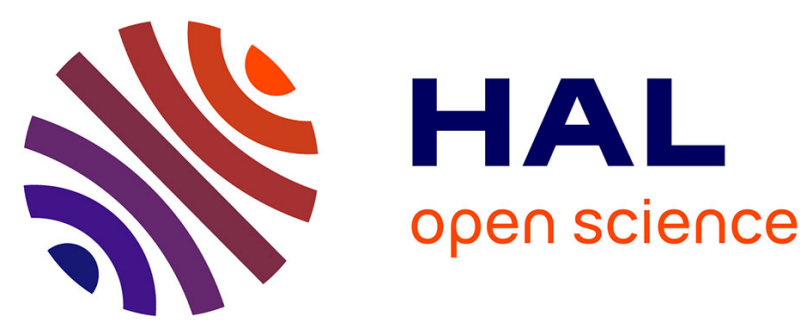

\title{
Regulation of GluA1 Phosphorylation by D-amphetamine and Methylphenidate in the Cerebellum
} Laura Cutando, Emma Puighermanal, Laia Castell, Pauline Tarot, Federica Bertaso, Patricia Bonnavion, Alban de Kerchove D'exaerde, Elsa Isingrini, Micaela Galante, Glenn Dallérac, et al.

\section{To cite this version:}

Laura Cutando, Emma Puighermanal, Laia Castell, Pauline Tarot, Federica Bertaso, et al.. Regulation of GluA1 Phosphorylation by D-amphetamine and Methylphenidate in the Cerebellum. Addiction Biology, 2021, 26 (4), pp.e12995. 10.1111/adb.12995 . hal-03451525

\section{HAL Id: hal-03451525 \\ https://hal.science/hal-03451525}

Submitted on 26 Nov 2021

HAL is a multi-disciplinary open access archive for the deposit and dissemination of scientific research documents, whether they are published or not. The documents may come from teaching and research institutions in France or abroad, or from public or private research centers.
L'archive ouverte pluridisciplinaire HAL, est destinée au dépôt et à la diffusion de documents scientifiques de niveau recherche, publiés ou non, émanant des établissements d'enseignement et de recherche français ou étrangers, des laboratoires publics ou privés.

\section{(c)(1)}

Distributed under a Creative Commons Attribution| 4.0 International License 


\section{Regulation of GluA1 Phosphorylation by D-amphetamine and Methylphenidate in the}

\section{Cerebellum.}

Laura Cutando ${ }^{1}$, Emma Puighermanal ${ }^{1 *}$, Laia Castell ${ }^{1}$, Pauline Tarot $^{1}$, Federica Bertaso ${ }^{1}$, Patricia Bonnavion ${ }^{2}$, Alban de Kerchove d'Exaerde ${ }^{2}$, Elsa Isingrini ${ }^{3,4}$, Micaela Galante ${ }^{5}$, Glenn Dallerac $^{5}$, Vincent Pascoli ${ }^{6}$, Christian Luscher ${ }^{6}$, Bruno Giros $^{3,4}$, Emmanuel Valjent $^{1}$

${ }^{1}$ IGF, Univ. Montpellier, CNRS, Inserm, F-34094 Montpellier, France.

${ }^{2}$ Laboratory of Neurophysiology, ULB Neuroscience Institute, Université Libre de Bruxelles (ULB), 1070 Brussels, Belgium.

${ }^{3}$ Université de Paris, CNRS, Integrative Neuroscience and Cognition Center, F-75006 Paris, France.

${ }^{4}$ Department of Psychiatry, Douglas Hospital, McGill University, Montreal, Quebec, Canada. ${ }^{5}$ Pharmacologie et Biochimie de la Synapse, Institut des Neurosciences Paris-Saclay, Université Paris-Saclay, Université Paris-Sud - CNRS, UMR 9197, Orsay, France.

${ }^{6}$ Department of Basic Neurosciences, Medical Faculty, University of Geneva, CH-1211 Geneva, Switzerland

\footnotetext{
* Present address Neurosciences Institute, Department of Cell Biology, Physiology and Immunology, Autonomous University of Barcelona, Bellaterra, Spain.
}

Key words (5 to 7 words): Prescription stimulants, Cerebellar Cortex, Bergmann Glia Cells, GluA1, Monoaminergic system. 


\section{Abbreviations:}

BGCs: Bergmann Glia Cells

PC: Purkinje cells

CC: Cerebellar Cortex

DA: Dopamine

NE: Noradrenaline

D1R: Dopamine D1 receptor

$\beta$-AR: Beta-adrenergic receptors

$\beta 1$-AR: Beta-1-adrenergic receptors

AC: Adenylyl cylase

PKA: Protein Kinase A

PKC: Protein Kinase C

AMPA: $\alpha$-amino-3-hydroxy-5-methyl-4-isoxazolepropionic acid

GluA1: AMPA subunit A1

DAT: Dopamine transporter

TH: Tyrosine hydroxylase

VMAT2: Vesicular monoamine transporter 2

VTA: Ventral Tegmental Area

SN: Substantia nigra

LC: Locus Coeruleus

D-amph: D-amphetamine

Mph: Methylphenidate

ADHD: attention-deficit/hyperactivity disorder

HA: hemagglutinin 


\section{Abstract (250 words)}

Prescription stimulants, such as d-amphetamine or methylphenidate, are potent dopamine (DA) and norepinephrine (NE) releasers used to treat children and adults diagnosed for attentiondeficit/hyperactivity disorder (ADHD). Although increased phosphorylation of the AMPA receptor subunit GluA1 at Ser845 (pS845-GluA1) in the striatum has been identified as an important cellular effector for the actions of these drugs, regulation of this posttranslational modification in the cerebellum has never been recognized. Here, we demonstrate that damphetamine and methylphenidate increase pS845-GluA1 in the membrane fraction in both vermis and lateral hemispheres of the mouse cerebellum. This regulation occurs selectively in Bergmann Glia Cells and requires intact norepinephrine release since the effects were abolished in mice lacking the vesicular monoamine transporter-2 selectively in NE neurons. Moreover, d-amphetamine-induced pS845-GluA1 was prevented by $\beta 1$-adenoreceptor antagonist, whereas the blockade of dopamine D1 receptor had no effect. Additionally, we identified transcriptional alterations of several regulators of the cAMP/PKA pathway, which might account for the absence of pS845-GluA1 desensitization in mice repeatedly exposed to damphetamine or methylphenidate. Together, these results point to norepinephrine transmission as a key regulator of GluA1 phosphorylation in Bergmann Glial Cells, which may represent a new target for the treatment of ADHD. 


\section{Introduction}

Attention-deficit/hyperactivity disorder (ADHD) is a neurodevelopmental disorder characterized by a myriad of symptoms including distractibility, hyperactivity and impulsivity (Wilens and Spencer, 2010). Children and adults diagnosed for ADHD are generally treated with stimulant medications such as d-amphetamine (Adderrall ${ }^{\circledR}$ ) and methylphenidate (Ritaline ${ }^{\circledR}$ ), whose non-medical use and abuse are becoming increasingly prevalent among the general population (Lakhan and Kirchgessner, 2012). Thus, a better understanding of the molecular actions of stimulant exposure on brain function is needed.

The therapeutic efficacy of these drugs as well as their ability to precipitate the development of substance use disorders mainly rely on their actions on dopaminergic and noradrenergic systems (Engert and Pruessner, 2008; Gatley et al., 1996; Pierce and Kalivas, 1997; Sulzer et al., 1995; White and Kalivas, 1998). By rising up extracellular concentrations of dopamine (DA) and norepinephrine (NE) in the striatum and the prefrontal cortex, these drugs increase alertness and attention therefore improving ADHD symptoms (Kuczenski and Segal, 1997) but can also hijack reward processing, motivation, motor and executive functions in case of misuse (Weyandt et al., 2016). Given the widespread DA and NE projections throughout the central nervous system, stimulant-induced molecular adaptations may also exist in other brain regions.

Although the cerebellum has never been considered as a primary site of actions of stimulant medications, compelling evidence indicates that these drugs alter cerebellar neuronal activity as well as monoamine turnover (Freedman and Marwaha, 1980; Quansah et al., 2018; Sorensen et al., 1982) and ameliorate some of the cerebellar abnormalities associated to ADHD symptoms (Stoodley, 2016). The endogenous monoaminergic system is prominent in the cerebellum. Dopaminergic and noradrenergic projections to the cerebellum arise from midbrain DA neurons (VTA/SNc) and hindbrain NE neurons (LC) (Chrapusta et al., 1994; Glaser et al., 2006; Ikai et al., 1994; Ikai et al., 1992; Melchitzky and Lewis, 2000; Nelson et al., 1997; 
Panagopoulos et al., 1991; Saigal et al., 1980; Saint-Mleux et al., 2004). They modulate the activity of both cerebellar neurons and glial cells, which express a large repertoire of dopaminergic and adrenergic receptors (Juorio et al., 1993; Li et al., 1992; Salm and McCarthy, 1992). However, no work to date has addressed the regulation of intracellular signaling events following stimulants exposure in the cerebellum.

Phosphorylation is a posttranslational modification enabling the rapid functional regulation of proteins. A typical example of such process is the GluA1 subunit of the glutamate $\alpha$-amino3-hydroxy-5-methyl-4- isoxazolepropionic acid (AMPA) receptor, which undergoes phosphorylation on two serine residues (pS845 and pS831) achieved by cAMP-dependent protein kinase (PKA) (for pS845) and by calcium/calmodulin-dependent (CaMKII) and protein kinase C (PKC) (for pS831), respectively (Mammen et al., 1997; Roche et al., 1996). Phosphorylation of these two sites directly regulates surface trafficking of GluA1 and its interaction with intracellular proteins as well as electrophysiological properties of AMPA receptors (Roche et al., 1996; Wang et al., 2005). Levels of GluA1 phosphorylation have been reported to be sensitive and modulated by stimulant exposure. For example, acute damphetamine and methylphenidate administration increases pS845-GluA1, but not pS831GluA1, in both the striatum and the prefrontal cortex (Mao et al., 2013; Pascoli et al., 2005; Valjent et al., 2005). AMPA receptors are also widely distributed in the cerebellum (Longone et al., 1998; Martin et al., 1993; Petralia and Wenthold, 1992). However, GluA1 subunit is exclusively expressed by a unique type of astrocyte involved in a wide range of cerebellar functions, the Bergmann Glial cells (BGCs) (De Zeeuw and Hoogland, 2015; Douyard et al., 2007; Saab et al., 2012).

In this study, we probed the ability of d-amphetamine and methylphenidate to modulate GluA1 phosphorylation in BGCs. We also investigated the contribution of DA and NE 
bioRxiv preprint doi: https://doi.org/10.1101/2020.07.10.196766; this version posted July 10, 2020. The copyright holder for this preprint

(which was not certified by peer review) is the author/funder, who has granted bioRxiv a license to display the preprint in perpetuity. It is made available under aCC-BY-NC-ND 4.0 International license.

transmission in the control of stimulants-induced GluA1 phosphorylation and determined the impact of repeated exposure to stimulant medications on these intracellular signaling events. 


\section{Materials and Methods}

\section{Animals}

Eight-week-old male C57BL/6 were purchased from Charles River Laboratories. The different transgenic mouse lines used are detailed in Supplementary Table 1. Mice were housed under standardized conditions with a $12 \mathrm{~h}$ light/dark cycle, stable temperature $\left(21 \pm 2{ }^{\circ} \mathrm{C}\right)$, controlled humidity $(55 \pm 10 \%)$, and food and water ad libitum. All experiments were in accordance with the guidelines of the French Agriculture and Forestry Ministry for handling animals (authorization number/license D34-172-13). Mice were arbitrarily assigned to pharmacological treatments. The number of animals used in each experiment is reported in the figure legends. No statistical methods were used to predetermine sample sizes, but they are comparable to those generally used in the field. For characterization experiments (immunofluorescence, polysome IP, qRT-PCR) male and female mice were used. For Western blot analyses, only male mice were used.

\section{Drugs}

(D)-Methylphenethylamine (D-amphetamine) sulfate salt, methylphenidate hydrochloride, cocaine, GBR12783, propranolol and betaxolol were from Sigma-Aldrich (St. Louis, MO, USA). SCH-23390 was from Tocris (Bristol, UK). All drugs were injected intraperitoneally (i.p.) in a body volume of $10 \mathrm{ml} / \mathrm{kg}$ and dissolved in $0.9 \%(\mathrm{w} / \mathrm{v}) \mathrm{NaCl}$ (saline) except GBR12783 which was dissolved in $\mathrm{H}_{2} \mathrm{O}$. Tamoxifen was dissolved in sunflower oil/ethanol (10:1) to a final concentration of $10 \mathrm{mg} / \mathrm{ml}$ and administered i.p. in a volume of $10 \mathrm{ml} / \mathrm{kg}(100$ $\mathrm{mg} / \mathrm{kg})$.

\section{Treatments}

Acute pharmacological treatments were carried out with saline, d-amph $(10 \mathrm{mg} / \mathrm{kg}), \mathrm{mph}(15$ 
$\mathrm{mg} / \mathrm{kg})$, cocaine $(20 \mathrm{mg} / \mathrm{kg})$ and GBR12783 (15 mg/kg). Mice were sacrificed $15 \mathrm{~min}$ after injections. The various antagonists were injected $30 \mathrm{~min}$ prior saline, d-amph $(10 \mathrm{mg} / \mathrm{kg})$ or $\mathrm{mph}(15 \mathrm{mg} / \mathrm{kg})$ injection. Propranolol and betaxolol were administered at $20 \mathrm{mg} / \mathrm{kg}$. SCH23390 at $0.1 \mathrm{mg} / \mathrm{kg}$. For chronic treatments, saline, d-amph $(10 \mathrm{mg} / \mathrm{kg})$ and $\mathrm{mph}(15 \mathrm{mg} / \mathrm{kg})$ were administered once per day during 5 days. Betaxolol $(20 \mathrm{mg} / \mathrm{kg})$ was administered $30 \mathrm{~min}$ prior saline, d-amph $(10 \mathrm{mg} / \mathrm{kg})$ or $\mathrm{mph}(15 \mathrm{mg} / \mathrm{kg})$ injection. Mice were killed $15 \mathrm{~min}$ after the fifth d-amph or mph administration. To induce the Cre expression in the Gfap$C_{r} e^{E R T 2}:: R i b o T a g$ mice (here referred as Gfap-RiboTag), tamoxifen (100 mg/kg) was administered during 3 consecutive days intraperitoneally in a volume of $10 \mathrm{ml} / \mathrm{kg}$.

\section{Stereotaxic injection in the VTA and the LC}

Stereotaxic injections in the VTA of Slc6a3-Cre mice have been performed as previously described (Pascoli et al., 2015). Six-week-old C57B16 Dbh-Cre mice were anaesthetized in isoflurane (4.0\% for induction, $0.5-1.0 \%$ for maintenance) in oxygen $(0.5 \mathrm{~L} / \mathrm{min})$ and mounted in a stereotaxic frame (Model 940, David Kopf Instruments). The skin on the head was shaved and aseptically prepared, and $2 \mathrm{mg} / \mathrm{kg}$ lidocaine infused subcutaneously at the incision site. A single longitudinal midline incision was made from the level of the lateral canthus of the eyes to the lambda skull suture. Injections were performed using a 30-gauge needle (Cooper's needle Works Ltd) connected by PBS $0.01 \mathrm{M}$-filled tubing to a $10-\mu \mathrm{L}$ Hamilton syringe in an infusion pump (KDS 310 Plus Nano Legacy Syringe Pump, KD Scientific). Injections were performed at $0.1 \mu \mathrm{L} / \mathrm{min}$ and the needle left in situ for $15 \mathrm{~min}$ afterwards to allow diffusion. Injections were performed in LC (AP $-5.4 \mathrm{~mm}$ from bregma skull suture, $\mathrm{ML}+/-1.2 \mathrm{~mm}, \mathrm{DV}-3 \mathrm{~mm}$ from brain surface, $800 \mathrm{~nL}$ ). Coordinates based on the mouse brain atlas (Franklin and Paxinos, 2008). Animals received Cre-inducible recombinant AAV vector prepared by the viral vector core at the University of North Carolina (lot AV4311c, $3.6 \times 10^{12}$ genome copies $(\mathrm{gc}) / \mathrm{mL}$ ) 
AAV2.5-EF1a-DIO-Cherry for anatomical tracing of LC NE neurons projections. Animals were allowed to recover in individual housing after surgery and we awaited at least 8 to 12 weeks for transgene expression in terminals before being killed for histology.

\section{Tissue preparation and immunofluorescence}

Tissue preparation and immunofluorescence were performed as previously described (Biever et al., 2015). Mice were rapidly anaesthetized with Euthasol ${ }^{\circledR}(360 \mathrm{mg} / \mathrm{kg}$, i.p., TVM lab, France) and transcardially perfused with $4 \%$ (weight/vol) paraformaldehyde in $0.1 \mathrm{M}$ sodium phosphate buffer ( $\mathrm{pH}$ 7.5). Brains were post-fixed overnight in the same solution and stored at $4^{\circ} \mathrm{C}$. Forty- $\mu \mathrm{m}$ thick sections were cut with a vibratome (Leica, France) and stored at $-20^{\circ} \mathrm{C}$ in a solution containing 30\% (vol/vol) ethylene glycol, 30\% (vol/vol) glycerol and $0.1 \mathrm{M}$ sodium phosphate buffer, until they were processed for immunofluorescence. Sagittal cerebellar sections were identified using a mouse brain atlas (Franklin and Paxinos, 2008) and were processed as follows: free-floating sections were rinsed three times $10 \mathrm{~min}$ in Tris-buffered saline (TBS, $50 \mathrm{mM}$ Tris-HCL, $150 \mathrm{mM} \mathrm{NaCl}, \mathrm{pH}$ 7.5). After $20 \mathrm{~min}$ incubation in $0.1 \%$ (vol/vol) Triton X-100 in TBS, sections were rinsed in TBS again during $10 \mathrm{~min}$ and blocked for $1 \mathrm{~h}$ in a solution of 3\% BSA in TBS. Cerebellar sections were then incubated 72 hours at $4^{\circ} \mathrm{C}$ with the primary antibodies (Supplementary Table 2) diluted in a TBS solution containing $1 \%$ BSA and $0.15 \%$ Triton $\mathrm{X}-100$. Sections were rinsed three times for $10 \mathrm{~min}$ in TBS and incubated for 60 min with goat Cy3-coupled anti-rabbit (1:500, Thermo Fisher Scientific Cat\# 10520), goat Alexa Fluor 594-coupled anti-chicken (1:400, Thermo Fisher Scientific Cat\#A11042), goat Alexa Fluor 488-coupled anti-chicken (1:500, Thermo Fisher Scientific Cat\#A11039), goat Alexa Fluor 488-coupled anti-mouse (1:500, Thermo Fisher Scientific Cat\#A11001), goat Alexa Fluor 488-coupled anti-rabbit (1:500, Life Technologies Cat\#A-11034), goat Cy5-coupled anti-mouse (1:500, Thermo Fisher Scientific Cat\#A-10524), goat Cy3- 
coupled anti-mouse (1:500, Jackson Immunoresearch Cat\#115-165-003) or goat Cy5-coupled anti-rabbit (1:500, Thermo Fisher Scientific, Cat\#A10523) antibodies. Sections were rinsed for 10 minutes (twice) in TBS and twice in Tris-buffer $(0.25 \mathrm{M}, \mathrm{pH} 7.5)$ before mounting in DPX (Sigma-Aldrich). Confocal microscopy and image analysis were carried out at the Montpellier RIO Imaging Facility. Images covering the entire cerebellum and double-labeled images from each region of interest were acquired using sequential laser scanning confocal microscopy (Zeiss LSM780). Photomicrographs were obtained with the following band-pass and long-pass filter setting: Alexa fluor 488/Cy2 (band pass filter: 505-530), Сy3 (band pass filter: 560-615) and Cy5 (longpass filter 650). All parameters were held constant for all sections from the same experiment. Three to four slices per mouse were used in all immunofluorescence analyses $(\mathrm{n}=$ 2-3 mice / staining).

\section{Tissue Collection and samples preparation for Western blot analysis}

Mice were killed by cervical dislocation and the heads were immersed in liquid nitrogen for 4 sec. The brains were then removed and sectioned on an aluminum block on ice and the whole cerebellum was rapidly isolated from the brainstem. For figures $2 \mathrm{a}$ and $2 \mathrm{~b}$ the whole cerebellum was sonicated in $300 \mu 1$ of $10 \%$ sodium dodecyl sulfate (SDS) and boiled at $95^{\circ} \mathrm{C}$ for $10 \mathrm{~min}$. For the other figures, subcellular fractionation was performed after tissue collection as previously described (Ozaita et al., 2007). In each experiment, samples from different animal groups, treatments or brain regions were processed in parallel to minimize inter assay variations.

\section{Western blot}

Protein quantification and western blots were performed following the protocol previously described (Biever et al., 2015). Following the manufacturer's instructions, protein contents for 
each sample were determined by BCA protein assay (Pierce) (Lot\# RG235624; Thermo Scientific). Equal amounts of cerebellar lysates were mixed with denaturing 4X Laemmli loading buffer. Samples with equal amounts of total protein were separated in $11 \%$ SDSpolyacrylamide gel before electrophoretic transfer onto Immobilon-P membranes (\#IPVH00010; Millipore). Membranes were cut horizontally, at different molecular weights to be analyzed with different primary antibodies. Using $4 \%$ bovine serum albumin (BSA) in $0.1 \mathrm{M}$ PBS, membranes were blocked for $45 \mathrm{~min}$, and then incubated for $2 \mathrm{~h}$ with the primary antibodies (Supplementary Table 2). To detect the primary antibodies, horseradish peroxidaseconjugated antibodies (1:10000) from Cell Signaling Technology to rabbit (Cat\# 7074S) or mouse (Cat\#7076S) were used, and visualized by enhanced chemiluminescence detection (Luminata Forte Western HRP Substrate; Millipore, Cat\# WBWF0500). The optical density of the relevant immunoreactive bands was measured after acquisition on a ChemiDoc Touch Imaging System (Bio-Rad) controlled by Image Lab software version 3.0 (Bio-Rad). Representative cropped immunoblots for display were processed with Adobe Illustrator CS6. For quantitative purposes, the optical density values (O.D) of active phospho-specific antibodies were normalized to the detection of non-phospho-specific antibodies in the same sample and expressed as a percentage of control treatment or group. More specifically, in the Figures 2a, 2c, 4c, 4d, 5g, 6a, since the home-made stripping solution was not strong enough to ensure the removal of the first antibodies tested, the evaluation of pS845-GluA1 or p831-GluA1 and the total form GluA1 was performed in two different gels. The O.D of phospho-sites and the O.D of GluA1 were normalized gel to the O.D of control proteins $\beta$-actin or GADPH in each gel. Therefore, the analysis of the O.D was performed as follow: pS845-GluA1 or p831GluA1/ $\beta$-actin or GADPH (gel 1) versus GluA1/ $\beta$-actin or GADPH (gel 2). In Figures $2 b$ and 5d, GluA1 was evaluated after stripping of pS845-GluA1 or p831-GluA1. $\beta$-actin was assessed in the same gel. The analysis of the O.D was performed as follow: pS845-GluA1 or p831- 
GluA1 versus GluA1/ $\beta$-actin. Finally, in the Figure 6c O.D of pS845-GluA1 was directly normalized to O.D of GluA1. The number of samples and the statistical test used in each experiment are specified in the figure legends.

\section{Tissue collection for polysome immunoprecipitation}

Three weeks after the tamoxifen administration, male and female Gfap-RiboTag mice were killed by cervical dislocation and the heads were immersed in liquid nitrogen for $4 \mathrm{sec}$. The brains were then removed and sectioned on an aluminum block on ice and the whole cerebellum was rapidly isolated from the stem brain. Then, cerebellar samples were kept at $-80^{\circ} \mathrm{C}$ until they have been used to performed polysome immunoprecipitation (IP).

\section{Polyribosome immunoprecipitation and RNA extraction}

HA-tagged-ribosome immunoprecipitation in the cerebellum of Gfap-RiboTag mice was performed as it was previously described (Ceolin et al., 2017) using anti-HA antibody (5 $\mu 1 /$ sample; Biolegend; Cat\#901502) and magnetic beads (Invitrogen, \#100.04D). Total RNA contained in the pellet fraction was extracted from ribosome-mRNA complexes using RNeasy Microkit (Qiagen; Cat\#74004) and from the input fraction using the RNeasy Minikit (Qiagen; Cat\#74104) following manufacturer's instructions. Quality and quantity of RNA samples were both assessed using the Nanodrop 1000 spectrophotometer. Between 5 and 9 biological replicates, each one composed of a pool of 2 mice, were used for qRT-PCR analysis (Figures 1e, 4b, 5e and Supplemental Figure 5). For the RNA extraction in Figures 5c, 6b and 6d and the Supplemental Figure 4 we used the RNAeasy Minikit (Qiagen; Cat\#74104) following the manufacturer's instruction. 


\section{cDNA synthesis and quantitative real-time PCR}

After RNA extraction from pellet and the input fractions of CC Gfap-RiboTag mice, synthesis of cDNA was performed as it was previously described by using the SuperScript VILO cDNA synthesis kit (Invitrogen) in one cycle program consisting of $10 \mathrm{~min}$ at $25^{\circ} \mathrm{C}, 60 \mathrm{~min}$ at $42^{\circ} \mathrm{C}$, 5 min at $25^{\circ} \mathrm{C}$ and a final extension period of $5 \mathrm{~min}$ at $4^{\circ} \mathrm{C}$. Resulting cDNA was used for quantitative real-time PCR (qRT-PCR), using SYBR Green PCR master mix on the LC480 Real-Time PCR System (Roche) and the primer sequences reported in Supplemental Table 3. Analysis was performed using LightCycler 480 Software (Roche). In Figures 1e, 3c, 4b, 5e and Supplemental Figure 4, the immunoprecipitated mRNA (pellet fraction) was compared to the input fraction. Results are presented as linearized Ct-values and normalized to the housekeeping Tbp2a. $\Delta \Delta \mathrm{Ct}$ method was used to give the fold change. Five to nine biological replicates were used in these experiments. In Figure 5c and Supplemental Figure 4, results are presented as \% of change of VMAT2-cKO mice compared to control mice for each gene tested and normalized to the housekeeping gene $\operatorname{Tbp} 2 a$. In Figure 6, results are presented as $\%$ of change of chronic d-amphetamine or methylphenidate versus chronic saline for each gene tested and normalized to the housekeeping gene $\operatorname{Tbp} 2 a$.

\section{Single molecule fluorescent in situ hybridization}

For the examination of targeted RNA within intact cells, in situ hybridization RNAscope ${ }^{\circledR}$ technology was used following the protocol described by the supplier. Mice were decapitated and brains were frozen immediately on dry ice for $5 \mathrm{~min}$ and stored at $-80^{\circ} \mathrm{C}$. Brains were then sectioned at $-17^{\circ} \mathrm{C}$ with a cryostat at $14 \mu \mathrm{m}$ and mounted onto Superfrost Utra Plus slides (Thermo Scientific; Cat\# J4800AMNZ). Coronal cerebellar sections were collected from bregma -5.80 mm and -6.80 mm. Probes for Adrb1 (ACDBio; Mm-adrb1-C1Cat\# 449761) and Gfap (ACDBio; Mm-gfap-C3 Cat\#313211-C3) were used with the RNAscope Fluorescent 
Multiplex Kit (ACDBio; Cat\# 320850) as described by the supplier. Slides were counterstained for DAPI and mounted with ProLong Diamond Antifade mountant (Invitrogen; Cat\# P36961).

\section{Statistical analyses}

GraphPad Prism v6.0 software was used for statistical analyses. For normally distributed data, Student's t test was used. Multiple comparisons were performed by one-way or two-way ANOVA followed by Tukey's post-hoc analyses. All data are presented as mean $\pm \mathrm{SEM}$, and statistical significance was accepted at $5 \%$ level. ${ }^{*} \mathrm{p}<0.05, * * \mathrm{p}<0.01,{ }^{*} * \mathrm{p}<0.001$. All the statistics are presented in the Supplementary Table 4. 


\section{Results}

\section{GluA1 is expressed in Bergmann glia cells in the adult mouse cerebellum}

To confirm the preferential expression of GluA1 subunit of AMPA receptors in BGCs in the adult mouse cerebellum (Burnashev et al., 1992), we took advantage of the Ribotag methodology to isolate Grial transcripts from BGCs. We first generated Gfap-CreERT2RiboTag (Gfap-RiboTag) mice, which express the ribosomal protein Rpl22 tagged with hemagglutinin (HA) exclusively in astrocytes (Figure 1). Indeed, immunofluorescence analyses revealed that the vast majority of HA-positive cells had the typical morphology of BGCs with their cell bodies located in the PC layer and radial processes crossing the entire molecular layer. Moreover, these HA-positive cells co-localized with the astrocytic marker GFAP as well as with the glial glutamate/aspartate transporter GLAST-1 confirming their astrocytic nature (Figure 1a-b). In contrast, no co-localization was observed with neuronal (NeuN), Purkinje cells (PC) (Calbindin-D28k, DARPP-32) or microglial (Iba1) markers (Figure 1c-d). The specificity of Gfap-RiboTag mice was further validated by assessing the relative enrichment of astrocytic transcripts from mRNAs isolated after HAimmunoprecipitation on cerebellar extracts (Supplemental Figure 1). As expected, quantitative real time PCR (qRT-PCR) analyses revealed the enriched expression of several BGCs markers (Gfap, S100b, Vim, Slc1a3, Cdc42ep4, Lgi4, Dao, Acsbg1) (Koirala and Corfas, 2010) in the pellet fraction compared to the input fraction (Figure 1e). In contrast, transcripts which molecularly defined PC (Pcp2, Calb1), granule cells (Neurod1), Golgi cells (Grm2), unipolar brush cells (Grp), Lugaro cells (Acan), GABAergic interneurons (Lypd6, Noslap), microglia (Aifl), and oligodendrocytes (Cnp) were all depleted (Figure 1e). In this GfapRiboTag mouse model, qRT-PCR analysis revealed that Grial transcripts were enriched after HA-immunoprecipitation (Figure 1e). The preferential expression of GluA1 in the molecular layer of the cerebellar cortex was confirmed by immunofluorescence (Figure 1f). Altogether, 
these results confirmed previous work revealing that GluA1 is preferentially expressed in BGCs in the adult mouse cerebellum (Petralia and Wenthold, 1992).

\section{D-amphetamine and methylphenidate increase GluA1 phosphorylation at serine 845 in}

\section{the cerebellum}

Acute administration of psychostimulant drugs, such cocaine or d-amphetamine triggers a rapid increase of GluA1 phosphorylation at serine 845 (pS845-GluA1) in the striatum and prefrontal cortex (Pascoli et al., 2005; Snyder et al., 2000; Valjent et al., 2005). To evaluate whether psychostimulants could produce similar effects in the cerebellum, C57/B16 mice were treated with d-amphetamine $(10 \mathrm{mg} / \mathrm{kg})$ and pS845-GluA1 was examined by Western blot in both the vermis and the lateral lobes of the cerebellum (Figure 2). Acute d-amphetamine administration, which produced hyperlocomotion and stereotypies within 15 min after injection (Pascoli et al., 2005), caused a rapid increase of pS845-GluA1 levels in the cerebellar vermis and lateral cerebellar hemispheres (Figure 2a). This effect was not accompanied by significant changes in the levels of total GluA1 detected with an antibody recognizing both the phosphorylated and unphosphorylated forms of GluA1 (Figure 2a). Moreover, subcellular fractionation of cerebellar lysates from mice injected with saline or d-amphetamine showed that pS845-GluA1 increases specifically in the in the membrane compartment (Figure 2b). In contrast, acute damphetamine failed to regulate GluA1 phosphorylation at serine 831 (pS831-GluA1) (Figure 2a-b). Similarly, an increase of pS845-GluA1 $(\mathrm{p}=0.055)$ was observed in mice administered with methylphenidate $(15 \mathrm{mg} / \mathrm{kg})$, a psychostimulant drug commonly used for the treatment of ADHD (Figure 2c) (Wilens et al., 2002). Interestingly, a significant decrease of pS831-GluA1 was observed in the membrane fraction of methylphenidate-treated mice (Figure 2c). Altogether, these results indicate that acute d-amphetamine or methylphenidate administration selectively enhances GluA1 phosphorylation at serine 845 which most likely occurred in BGCs. 


\section{Regulation of pS845-GluA1 in BGCs in response to d-amphetamine is independent from cerebellar dopamine signaling}

D-amphetamine increases the extracellular concentration of dopamine (DA) availability in various brain areas (Kuczenski et al., 1997). We therefore conducted a series of experiments to determine whether DA signaling participates to the regulation of pS845-GluA1 by damphetamine in the cerebellum. Immunofluorescence analyses revealed the presence of a dense lattice of TH-positive fibers and a strong VMAT2 immunoreactivity in the molecular layer suggesting that DA could be potentially released in the cerebellar cortex (Supplemental Figure 2a-b). We first asked whether the VTA/SN constitute a source of dopaminergic fibers in the cerebellar cortex. To do so, midbrain DA axons were anterogradely labeled by injecting a Credependent virus (AAV8-hSyn-FLEX-ChrimsonR-tdTomato) in the VTA/SN of Slc6a3-Cre mice, expressing the Cre recombinase under the promotor of the dopamine transporter (DAT) (Figure 3a). Viral transduction of midbrain DAT-positive neurons resulted in sparse axonal labeling in the PC and molecular layers detected using an antibody directed against the red fluorescent protein (RFP) (Figure 3b and Supplemental Figure 3). In the molecular layer RFP-positive fibers are oriented in the same axis of PC being in close proximity of BGCs identified using anti-GFAP antibody (Figure $\mathbf{3 b}$ ). These results indicate that midbrain constitutes a potential source of dopaminergic input for the cerebellum.

In various brain regions, astrocytes express, although at low levels, transcripts encoding proteins involved DA metabolism (Juorio et al., 1993; Li et al., 1992). We therefore evaluated the expression of transcripts encoding enzymes involved in DA biosynthesis $(D d c, T h)$ as well as the dopamine transporter DAT (Slc6a3) among mRNAs isolated after HAimmunoprecipitation in cerebellar extracts of Gfap-RiboTag mice (Figure 3c). Our qRT-PCR analysis revealed that the expression of Slc6a3 was enriched in cerebellar GFAP-positive cells 
(Figure 3c). In contrast, no changes were observed for $T h$ and $D d c$ transcripts, which encode for the tyrosine hydroxylase and the aromatic l-amino acid decarboxylase, respectively (Figure 3c). The presence of DAT in BGCs was further supported by the analysis of YFP expression in the cerebellar cortex of DAT-YFP mice (Figure 3d). Thus, sparse cerebellar YFP-expressing cells, which displayed typical BGCs morphology, co-expressed the astrocytic marker GFAP but not the GABAergic marker PV (Figure 3d). These findings indicate that DAT is expressed by a fraction of BGCs raising the possibility that BGCs reuptake DA in the cerebellum. Altogether, our results identify at least two potential sites through which DA could be released and possibly participate to the regulation of pS845-GluA1.

In the striatum, d-amphetamine-induced pS845-GluA1 depends on cAMP-dependent protein kinase (PKA) activation downstream the stimulation of dopamine D1 receptors (D1R) (Snyder et al., 2000; Valjent et al., 2005). Despite early evidence suggesting the presence of D1R in the molecular layer of the cerebellum (Camps et al., 1990; Savasta et al., 1986), the cellular identity of D1R-expressing cells in the cerebellar cortex remains largely unknown. To address this issue, we analyzed the distribution of GFP-positive cells in the cerebellar cortex of D1-eGFP mice (Figure 4). In all the lobules, a strong GFP labeling was found in the molecular layer of the cerebellar cortex (Figure 4a). Detailed analysis revealed that GFP-positive cells expressed GFAP, a marker of astrocytes, presumably corresponding to BGCs, but not the PC marker CB (Figure 4a). The presence of D1R in BGCs was further supported by the enrichment of Drdl transcripts among the mRNAs isolated following HA-immunoprecipitation in cerebellar extracts of Gfap-RiboTag mice (Figure 4b). In contrast, no differences were observed for Drd2 and Drd3 transcripts (Figure 4b). Together, these results indicate that D1R are expressed in BGCs.

To assess whether D1R participates to the regulation of GluA1 phosphorylation induced by d-amphetamine in BGCs, C57/B16 mice were administered with SCH23390 (0.1 mg/kg), a 
D1R/D5R-selective antagonist, 30 min prior the injection of d-amphetamine or saline. As shown in Figure 4, blockade of D1R/D5R had no effect on the basal or increased GluA1 phosphorylation at S845 induced by d-amphetamine measured in membrane fractions (Figure 4c). These results suggest that DA may not be necessary to enhance GluA1 phosphorylation in BGCs in response to d-amphetamine. We therefore evaluated whether increasing the extracellular concentration of DA was sufficient to trigger pS845-GluA1 in the cerebellum. To do so, we measured the effect of cocaine $(20 \mathrm{mg} / \mathrm{kg})$ and GBR12783 (15 mg/kg), a selective DA reuptake inhibitor, on the phosphorylation of GluA1 at S845. Although both drugs enhanced locomotor activity 15 min after administration (Valjent et al., 2010), they failed to increase pS845-GluA1 in BG (Figure 4d). Similar results were obtained following the acute administration of the D1R/D5R agonist, SKF81297 (data not shown). Altogether, our findings indicate that d-amphetamine-induced GluA1 phosphorylation at S845 in BGCs does not involve DA transmission.

\section{D-amphetamine-induced increase of pS845-GluA1 requires noradrenergic transmission}

In addition to its ability to release DA, d-amphetamine is also a potent releaser of norepinephrine (Kuczenski and Segal, 1997). We therefore examined whether the cerebellar cortex received noradrenergic-projecting neurons from the locus coeruleus (LC), the major noradrenergic nucleus of the brain (Saigal et al., 1980; Saint-Mleux et al., 2004). To selectively label hindbrain NE axons, we injected a Cre-dependent virus (AAV2.5-EF1a-DIO-mCherry) in the LC of mice expressing the Cre-recombinase under the dopamine $\beta$-hydroxylase promoter (Dbh-Cre mice) (Figure 5a). As shown in Figure 5, RFP-positive fibers were detected in the PC and molecular layers indicating that NE neurons from the LC constitute a source of noradrenergic input for the cerebellum (Figure 5b).

We therefore investigated whether the noradrenergic transmission was involved in the 
increased pS845-GluA1 induced by d-amphetamine administration. To address this issue, we used conditional Slc18a2 knock-out mice (VMAT2-cKO) previously generated by crossing the Dbh-Cre mouse line with Slc18a2 $2^{\text {loxP } / l o x P}$ mice (Isingrini et al., 2016). As revealed by qRT-PCR analysis performed on cerebellar extracts, deletion of Slc18a2 in DBH neurons neither altered level of transcripts encoding receptors (Drd1, Drd2, Drd3, Adrb1, Adrb2, Adrala) transporters (Slc6a3), and enzymes involved in catecholamine biosynthesis (Ddc, Th) and degradation (Comt, Maoa, Maob), nor changed the expression of Grial transcripts (Figure 5c and Supplemental Figure 4). In addition, no changes were detected in the expression of transcripts enriched in glial cells including BGCs (Gfap, Itgam, Aif1, Apq4, Kcnj10) and PC (Gria2). We then measured d-amphetamine-induced pS845-GluA1 in VMAT2-cKO. While cerebellar GluA1 expression was unaffected by the deletion of Slc18a2 in the DBH neurons, the increase of pS845-GluA1 observed following d-amphetamine administration was totally abolished in VMAT2-cKO (Figure 5d). These results indicate that noradrenergic transmission is necessary for the regulation of GluA1 phosphorylation by d-amphetamine in BGCs.

We next investigated whether d-amphetamine-induced PKA-dependent GluA1 phosphorylation in BGCs required $\beta$-Adrenergic receptors ( $\beta$-AR) which, upon agonist activation stimulate the cAMP/PKA pathway (Gelinas et al., 2008; Maguire et al., 1977). Using mRNAs isolated after HA-immunoprecipitation in cerebellar extracts of Gfap-RiboTag mice, we determined the relative abundance of $A d r b 1$ and $A d r b 2$ transcripts encoding $\beta 1$-AR and $\beta 2-$ AR, respectively (Figure 5e). Our analysis revealed that $A d r b 1$, but not $A d r b 2$, transcripts were significantly enriched in cerebellar GFAP-positive cells (Figure 5e). Of note, Adrala transcripts encoding $\alpha$ la-AR, which are highly expressed in BGCs (Doyle et al., 2008), were also detected after HA-immunoprecipitation (Figure 5e). Single molecule fluorescent in situ hybridization analysis further confirmed the preferential expression of $A d r b 1 \mathrm{mRNAs}$ in BGCs, identified here by Gfap transcripts in the PC layer (Figure 5f). To evaluate the contribution $\beta 1$ - 
$\mathrm{AR}$ in the regulation of GluA1 phosphorylation triggered by d-amphetamine, C57/B16 mice were administered with either propranolol, a general $\beta$-AR antagonist $(20 \mathrm{mg} / \mathrm{kg}$; i.p), or betaxolol, a selective $\beta 1-\mathrm{AR}$ antagonist (20 mg/kg; i.p) $30 \mathrm{~min}$ prior the injection of $\mathrm{d}$ amphetamine or saline (Figure 5g). As revealed by Western blot analyses, d-amphetamine failed to increased GluA1 phosphorylation in presence of both antagonists (Figure 5g). Altogether, these findings indicate that d-amphetamine-induced pS845-GluA1 in BG requires noradrenergic transmission and $\beta 1-\mathrm{AR}$ activation.

\section{Repeated exposure to d-amphetamine and methylphenidate enhances pS845-GluA1 in BGCs through $\beta 1-A R$ activation}

Long-term exposure to d-amphetamine or methylphenidate induce a variety of neuronal changes that contribute to the development of long-lasting behavioral alterations (refs). We next investigated whether the ability of d-amphetamine to trigger pS845-GluA1 was preserved following repeated exposure and if so, whether it still relied on $\beta 1$-AR activation. To address this issue, C57/B16 mice received saline or d-amphetamine $(10 \mathrm{mg} / \mathrm{kg})$ for 5 consecutive days. Before each administration, mice were pretreated with betaxolol $(20 \mathrm{mg} / \mathrm{kg})$ or its vehicle. The level of pS845-GluA1 was analyzed in cerebellar membrane fractions 15 min after the last injection of saline or d-amphetamine. Western blot analysis revealed that the ability of damphetamine to increase pS845-GluA1 in BGCs was preserved in mice repeatedly exposed to d-amphetamine (Figure 6a). This increased phosphorylation still relied on $\beta 1$-AR activation since pS845-GluA1 was totally prevented in mice pretreated with betaxolol (Figure 6a).

We next examined whether repeated exposure to d-amphetamine induced transcriptional alterations of genes encoding proteins involved in the regulation of cAMP/PKA pathway turnover. To address this question, we compared by qRT-PCR the expression level of several BGCs-enriched transcripts between mice repeatedly administered with saline or d- 
amphetamine (Figure 6b and Supplemental Figure 5). Our analysis revealed a significant increase of $A d r b 1$ and $A c d y 2$ transcripts encoding $\beta 1$-AR and adenylate cyclase 2 in mice exposed 5 consecutive days to d-amphetamine (Figure 6b). Conversely, Pde7b, Ppmla and Ppp1r14c mRNAs encoding phosphodiesterase 7B, protein phosphatase, $\mathrm{Mg}^{2+} / \mathrm{Mn}^{2+}$ dependent $1 \mathrm{~A}$ and protein phosphatase 1 regulatory subunit $14 \mathrm{C}$, respectively, were reduced upon this damphetamine-treatment regimen (Figure 6b). Similar results were obtained in mice repeatedly exposed to methylphenidate (Figure 6c-d). Altogether, these results indicate that $\beta 1$-ARdependent GluA1 phosphorylation in BGCs is preserved in mice repeatedly exposed to damphetamine or methylphenidate. Moreover, our findings identify BGCs transcriptional alterations of several regulators of the cAMP/PKA pathway, which account for the absence of pS845-GluA1 desensitization. 


\section{Discussion}

The present findings show that systemic administration of d-amphetamine and methylphenidate enhanced cAMP/PKA-regulated phosphorylation of GluA1 subunit of the AMPA receptors in BGCs. They also revealed that this regulation requires intact NE transmission and the activation of $\beta 1$-AR. Finally, our study identified transcriptional alterations of several components of the cAMP/PKA pathway which may account for the maintenance of the stimulant medications ability to increase GluA1 phosphorylation following drug administration. These results suggest that BGCs may represent a key component in the efficacy of these drugs to alleviate ADHD symptoms.

GluA1 phosphorylation is an important process regulating AMPA receptors functions in response to a variety of stimuli (Roche et al., 1994). The regulation of GluA1 phosphorylation in response to psychostimulants is certainly one of the best characterized. Here we demonstrate a rapid and selective increase of GluA1 phosphorylation at S845 in the cerebellum following d-amphetamine and methylphenidate administration. Our results extend previous observations identifying similar regulatory mechanisms in other brain regions by a wide range of psychostimulants (Choi et al., 2011; Li et al., 2011; Mao et al., 2013; Pascoli et al., 2005; Snyder et al., 2000; Valjent et al., 2005; Xue et al., 2014). Importantly, our data suggest that each psychostimulant generate specific patterns of GluA1 phosphorylation, as it is the case for ERK pathway (Valjent et al., 2004 57). Thus, increased pS845-GluA1 in the cerebellum was not induced by cocaine but instead only observed following the administration of stimulant medications. This contrasts with the striatum, where enhanced GluA1 phosphorylation occurs in response to all psychostimulants (Ferrario et al., 2011; Mao et al., 2013; Snyder et al., 2000; Valjent et al., 2005). The ability of cocaine vs stimulant medications to recruit distinct monoaminergic circuits certainly account for the specificity of GluA1 phosphorylation patterns 
induced by these drugs. Thus, in densely DA-innervated regions such as the striatum, psychostimulants-induced pS845-GluA1 is mediated primarily through D1R activation (Mao et al., 2013; Snyder et al., 2000; Valjent et al., 2005). In contrast, our study reveals that in the cerebellum, in which both DA and NE extracellular concentrations increased following damphetamine and methylphenidate administration (Goldstein and Macmillan, 1993; Krobert et al., 1994; Quansah et al., 2018), GluA1 phosphorylation relies exclusively on intact NE transmission and $\beta 1$-AR activation as it does in the prefrontal cortex (Pascoli et al., 2005; Xue et al., 2014). Interestingly, hippocampal GluA1 phosphorylation, which is enhanced by damphetamine (Mao et al., 2015), is also strongly regulated by NE and $\beta 1$-AR agonist (Hu et al., 2007; Tenorio et al., 2010) suggesting that the contribution of the noradrenergic system in the regulation of pS845-GluA1 by stimulant medications is certainly not restricted to the cerebellum and the prefrontal cortex.

Psychostimulant-induced pS845-GluA1 in the striatum and the prefrontal cortex occur in D1R- and 31 -AR-containing neurons (Pascoli et al., 2005; Snyder et al., 2000; Valjent et al., 2005). Our data clearly indicate that the ability of d-amphetamine or methylphenidate to enhance GluA1 phosphorylation is not specific to neurons but can also occur in astrocytes. In contrast to other brain regions, the expression of GluA1 subunit in the cerebellum is preferentially restricted to BGCs (Burnashev et al., 1992; Douyard et al., 2007; Matsui et al., 2005). In these glial cells GluA1-GluA4 containing AMPA receptors play an important role in regulating the astrocytic coverage of PC glutamatergic synapses (De Zeeuw and Hoogland, 2015; Ikai et al., 1994; Saab et al., 2012). Whether GluA1 phosphorylation at S845 in BGCs potentiates AMPA currents (Roche et al., 1996) and/or regulates surface trafficking of GluA1 (Serulle et al., 2007) as in neurons, remains to be established. Moreover, future studies will be necessary to determine whether d-amphetamine-induced pS845-GluA1 in BGCs is causally linked to the long-lasting $\beta$-AR-dependent reduction of PC firing rate induced by acute and 
repeated d-amphetamine exposure (Freedman and Marwaha, 1980; Sorensen et al., 1985; Sorensen et al., 1982).

Recent evidence indicates that depending on the vigilance states, astrocytes of the auditory cortex integrate NE activity through distinct signaling pathways. Thus, while transient NE release is accompanied with large cytosolic astrocytic $\mathrm{Ca}^{2+}$ elevations, sustained activity of noradrenergic neurons leads to a gradual increase of cAMP (Oe et al., 2020). Our results strongly suggest that similar regulations occur in BGCs since $\beta 1$-AR-mediated GluA1 phosphorylation induced by stimulant medications relies on sustained activity on LC NE neurons projecting to the cerebellum. Despite the lack of regulation of GluA1 phosphorylation

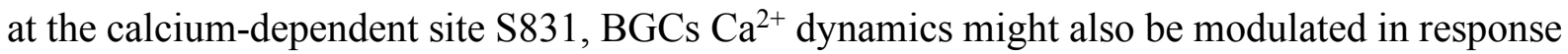

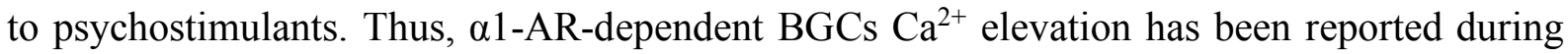
locomotion (Paukert et al., 2014), a behavioral response highly enhanced by d-amphetamine and methylphenidate exposure (Valjent et al., 2010). Moreover, acute d-amphetamine administration increases $\mathrm{Ca}^{2+}$ signaling in astrocytes in the nucleus accumbens though astrocytic D1R activation. Such regulatory mechanism is functionally important since it contributes to the modulation of both excitatory synaptic transmission and acute hyperlocomotor effects of d-amphetamine (Corkrum et al., 2020). Although D1Rs expressed in BGCs do not participate to the regulation of GluA1 phosphorylation, their potential role in the regulation of $\mathrm{BGCs} \mathrm{Ca}^{2+}$ signaling will require further investigation.

Structural and functional abnormalities in the cerebellum were amongst the first reported in patients diagnosed for ADHD. Thus, the severity of ADHD symptoms correlates to the extent of cerebellar volume reduction, which can be compensated by methylphenidate treatment (Bledsoe et al., 2009; Castellanos et al., 2002; Ivanov et al., 2014; Rubia et al., 2009). Interestingly, increased metabolic activity could be one of the mechanisms by which methylphenidate normalizes cerebellar dysfunction observed in ADHD (Volkow et al., 1998; 
Volkow et al., 1997). Supporting this hypothesis, methylphenidate has been shown to increases glutamate uptake in BGCs contributing to normalize impaired metabolic homeostasis reported in ADHD (Guillem et al., 2015). Future studies will determine whether disruption of cerebellar glutamate homeostasis may contribute to development of substance use disorders associated with the non-medical use of stimulant medications. 


\section{Acknowledgements}

We thank the iExplore, MRI and PVM Platforms of the IGF for their involvement in the maintenance and breeding of the colonies. This work was supported by Inserm, Fondation pour la Recherche Médicale (DEQ20160334919), La Marató de TV3 Fundació, ANR EPITRACES, ANR DOPAFEAR (EV), NARSAD Young Investigator Grant from the Brain and Behavior Research Foundation (EP) and CIHR project grant 201803PJT (BG). Laura Cutando is supported by the post-doctoral Labex EpiGenMed fellowship («Investissements d'avenir» ANR-10-LABX-12-01), EP was a recipient of Marie Curie Intra-European Fellowship IEF327648 and is currently a recipient of a Beatriu de Pinós fellowship (\# 2017BP00132) from the University and Research Grants Management Agency (Government of Catalonia, Spain). Laia Castell is supported by the $\mathrm{PhD}$ Labex EpiGenMed fellowship («Investissements d'avenir» ANR-10-LABX-12-01). P.B and AKE are Research Associate and Research Director of the FRS-FNRS respectively and both are supported by FNRS, AKE is also supported by Foundation Simone and Pierre Clerdent. 


\section{Author contributions}

Laura Cutando, E.P and E.V conceived, designed and led the project. Laura Cutando and E.P performed brain dissections. Laura Cutando and E.P performed polysome IP and qRT-PCR experiments. Laura Cutando and F.B performed Western blot analyses. Laura Cutando, E.P and P.T performed immunofluorescence experiments. Laura Cutando and Laia Castell performed in situ hybridization analysis. M.G and G.D provided Gfap-CreERT2 mice and reagents. P.B and A.K performed stereotaxic injections in Dbh-Cre mice. V.P and C.L provided Slc6a3-Cre injected mice. E.I. and B.G generated and provided VMAT2-cKO mice. E.V supervised the project. Laura Cutando and E.V wrote the manuscript with input from all authors. The authors declare no conflicts of interest. 


\section{Figure Legends}

Figure 1. GluA1 are expressed in cerebellar astrocytes in adult mice. (a) Sagittal section from Gfap-RiboTag mice stained with HA (cyan) showing the distribution of GFAP-expressing cells in the cerebellar cortex. Scale bar: $400 \mu \mathrm{m}$ (left image). Double immunofluorescence for HA (cyan) and GFAP (magenta). Scale bar: $62 \mu \mathrm{m}$ (right images). (b-d) Triple immunofluorescence for HA (cyan), GFAP (magenta) and the astrocytic marker GLAST-1 (yellow) (b), the neuronal markers NeuN, Calbindin-D28k (CB), and DARPP-32 (yellow) (c), and the microglial marker Iba1 (d). Scale bar: $15 \mu \mathrm{m}$. (e) Validation by qRT-PCR $(\Delta \Delta \mathrm{CT})$ of the enrichment of glial markers (Cyan) and depletion of transcripts encoding PC, interneurons, oligodendrocyte and microglial markers after HA-immunoprecipitation from cerebellar extract compared with the input fraction $(n=5-6$ pooled samples of 2 mice $/$ pool). All genes were normalized to $\operatorname{Tbp} 2 \alpha$. Data were analyzed by two-sided $t$ test. ${ }^{*} p<0.05 ; * * p<0.01 ; * * * p<$ 0.001 (f) Double immunofluorescence in the cerebellar cortex for GluA1 (yellow) and GFAP (magenta). Scale bar: $60 \mu \mathrm{m}$. Note the expression of GluA1 in BGCs of the m.1. Scale bar: 100 $\mu \mathrm{m}$. PCl: Purkinje cell layer; g.l: granular layer; m.l: molecular layer. For detailed statistics see Supplementary Table 4.

\section{Figure 2. Acute psychostimulant administration increases S845 GluA1 phosphorylation}

in the cerebellum. (a) Representative immunoblots (left) and quantification (right) of GluA1 phosphorylation at S845 (pS845-GluA1) (top) or at S831 (pS831-GluA1) (bottom) in the vermis and lateral hemispheres of C57/B16 mice 15 minutes after a single administration of saline or d-amphetamine (d-amph, $10 \mathrm{mg} / \mathrm{kg}$ ). Phosphorylated forms of GluA1 were normalized to unphosphorylated GluA1. $\beta$-actin was used as housekeeping protein. Data are expressed as percentage of saline group $(n=4-5$ mice / group for vermis and lateral). Data are presented as means \pm SEM and analyzed by two-sided $t$ test. ${ }^{* *} p<0.01$. (b-c) Representative immunoblots 
(left) and quantification (right) of GluA1 phosphorylation at S845 (pS845-GluA1) (top) or at S831 (pS831-GluA1) (bottom) in membrane cerebellar extracts of C57/B16 mice 15 minutes after a single administration of saline, d-amphetamine (d-amph, $10 \mathrm{mg} / \mathrm{kg}$ ) (b) or methylphenidate (mph, $15 \mathrm{mg} / \mathrm{kg}$ ) (c). Phosphorylated forms of GluA1 were normalized to unphosphorylated GluA1. $\beta$-actin (b) and GAPDH (c) were used as housekeeping proteins. Data are expressed as percentage of saline group $(n=4-5$ mice / group for $d$-amph, $n=7$ mice / group for mph). Data are presented as means \pm SEM and analyzed by two-sided $t$ test. $* p<$ 0.05. For detailed statistics see Supplementary Table 4.

Figure 3. Sources of dopamine in the cerebellar cortex. (a) Scheme of Cre-dependent AAV9-CAG-Flex-TdTomato injection in the VTA of Slc6a3-Cre mice. (b) Double immunofluorescence for RFP (magenta), GFAP (cyan) (left) and calbindin-D28k (CB) (right) identifying RFP-expressing dopamine VTA neuron axons positive fibers in the cerebellar cortex. Note the orientation of RFP-positive fibers paralleling the BGCs. Scale bars: $60 \mu \mathrm{m}$ (left), $15 \mu \mathrm{m}$ (middle), $30 \mu \mathrm{m}$ (right). (c) qRT-PCR analysis of Slc6a3, Th and $D d c$ transcripts in cerebellar extracts from Gfap-RiboTag mice after HA-immunoprecipitation. All genes were normalized to $\operatorname{Tbp} 2 \alpha$. Data are presented as the fold change comparing the pellet fraction versus the input $(\mathrm{n}=4-5$ pooled samples of 2 mice / pool). Data were analyzed by two-sided $t$ test. $* * * p<0.001$. (d) Triple immunofluorescence for GFP (cyan), GFAP (magenta) and parvalbumin (PV; yellow) in the cerebellar cortex of Slc6a3-Cre mice crossed with the reporter mouse line ROSA26-YFP (DAT-YFP). Scale bar: $30 \mu \mathrm{m}$. PCl: Purkinje cell layer; g.l: granular layer; m.l: molecular layer. For detailed statistics see Supplementary Table 4.

Figure 4. D-amphetamine induced GluA1 phosphorylation in BGCs does not require D1R activation. (a) Sagittal section from D1-eGFP mice stained with GFP (cyan) showing the 
distribution of D1R-expressing cells in the cerebellar cortex. Scale bar: $1 \mathrm{~mm}$ (left image). Triple immunofluorescence for GFP (cyan), GFAP (magenta), and calbindin-D28k (CB, yellow) (right images). Scale bar: $30 \mu \mathrm{m}$. (b) qRT-PCR analysis of $\operatorname{Drd1}, \operatorname{Drd} 2$ and $\operatorname{Drd} 3$ transcripts in cerebellar extracts from Gfap-RiboTag mice after HA-immunoprecipitation. All genes were normalized to $\operatorname{Tbp} 2 \alpha$. Data are presented as the fold change comparing the pellet fraction versus the input $(n=4-5$ pooled samples of 2 mice / pool). Data were analyzed by twosided $t$ test. $* * * p<0.001$. (c) Representative immunoblots (left) and quantification (right) of GluA1 phosphorylation at S845 (pS845-GluA1) in the cerebellum of C57/B16 mice pretreated with the D1R/D5R antagonist, SCH23390 (0.1 mg/kg), 30 min prior saline or d-amphetamine (10 $\mathrm{mg} / \mathrm{kg}$ ) administration. Phosphorylated forms of GluA1 were normalized to unphosphorylated GluA1. $\beta$-actin was used as housekeeping protein. Data are expressed as percentage of saline group $(\mathrm{n}=5-6$ mice / group). Data are presented as means \pm SEM and analyzed by one-way ANOVA followed by Tukey post-hoc comparisons test. ${ }^{* *} p<0.01$. (d) Representative immunoblots (left) and quantification (right) of GluA1 phosphorylation at S845 (pS845-GluA1) in the cerebellum of C57/B16 mice administered with saline, GBR12783 (15 $\mathrm{mg} / \mathrm{kg}$ ) and cocaine $(20 \mathrm{mg} / \mathrm{kg})$. Phosphorylated forms of GluAl were normalized to unphosphorylated GluA1. $\beta$-actin was used as housekeeping protein. Data are expressed as percentage of saline group $(n=6$ mice / group). Data are presented as means \pm SEM and analyzed by one-way ANOVA followed by Tukey post-hoc comparisons test. PCl: Purkinje cell layer; g.1: granular layer; m.1: molecular layer. For detailed statistics see Supplementary Table 4.

Figure 5. D-amphetamine-induced p845-GluA1 requires intact NE transmission and $\beta 1$ AR activation. (a) Scheme of Cre-dependent AAV2.5-EF1a-DIO-mCherry injection in the LC of Dbh-Cre mice and representative images of transduced DBH neurons expressing mCherry 
(magenta) and TH (cyan). Scale bar: $50 \mu \mathrm{m}$. (b) RFP-expressing NE LC neuron axons positive fibers in the cerebellar cortex. Scale bar: $30 \mu \mathrm{m}$. (c) Expression of Grial, Drd1 and Adrb1 transcripts in cerebellar extracts of control and VMAT2-cKO mice. All genes were normalized to $\operatorname{Tbp} 2 \alpha$. Data are expressed as $\%$ of control $(\mathrm{n}=7$ mice). Results are represented as mean \pm SEM. Data were analyzed by two-sided $t$ test. (d) Representative (right) and quantification (right) of GluA1 phosphorylation at S845 in the cerebellar extracts of control and VMAT2cKO mice treated with saline or d-amphetamine $(10 \mathrm{mg} / \mathrm{kg}) . \beta$-actin was used as housekeeping protein. Data is expressed as a percentage of control mice treated with saline $(n=6-7$ mice $/$ group). Results are represented as mean \pm SEM and analyzed by two-way ANOVA followed by Bonferroni's post-hoc comparisons. (e) qRT-PCR analysis of Adrb1, Adrb2 and Adrala transcripts in cerebellar extracts from Gfap-RiboTag mice after HA-immunoprecipitation. All genes were normalized to $\operatorname{Tbp} 2 \alpha$. Data are presented as the fold change comparing the pellet fraction versus the input $(n=5-6$ pooled samples of 2 mice / pool). Data were analyzed by twosided $t$ test. ${ }^{* * *} p<0.001$. (f) Single molecule fluorescent in situ hybridization for Adrb1 (magenta) and Gfap (cyan) mRNAs in the cerebellar cortex. The slide was counterstained with DAPI (blue). Note that Adrbl mRNAs are preferentially expressed in astrocytes in the PC layer most likely corresponding to somas of BG. Scale bar: $15 \mu \mathrm{m}$. (g) Representative (right) and quantification (right) of GluR1 phosphorylation at S845 in the cerebellar extracts of C57/B16 mice pretreated with the $\beta 1 / 2-\mathrm{AR}$ antagonist propranolol $(20 \mathrm{mg} / \mathrm{kg}$ ) and $\beta 1-\mathrm{AR}$ antagonist betaxolol $(20 \mathrm{mg} / \mathrm{kg})$, respectively, $30 \mathrm{~min}$ prior saline or d-amphetamine $(10 \mathrm{mg} / \mathrm{kg})$ administration. Phosphorylated forms of GluA1 were normalized to unphosphorylated GluA1. $\beta$-actin was used as housekeeping protein. Data is expressed as a percentage of control mice treated with saline ( $n=5-6$ mice / group). Results are represented as mean \pm SEM and analyzed by one-way ANOVA followed by Tukey's post-hoc comparisons. ${ }^{* *} p<0.01$ saline $v s$. d-amph, \#\#\# $p<0.001$ sal/d-amph vs drug/d-amph. PCl: Purkinje cell layer; g.l: granular layer; m.l: 
molecular layer. For detailed statistics see Supplementary Table 4.

Figure 6. Effect of repeated exposure to d-amphetamine and methylphenidate on pS845-

GluA1 in the cerebellum. (a) Representative immunoblots (left) and quantification (right) of GluA1 phosphorylation at S845 (pS845-GluA1) in the cerebellum of C57/B16 mice pretreated with betaxolol $(20 \mathrm{mg} / \mathrm{kg}), 30 \mathrm{~min}$ prior each injection of saline or d-amphetamine $(10 \mathrm{mg} / \mathrm{kg}$, $1 \mathrm{inj} /$ day during 5 days). Phosphorylated forms of GluA1 were normalized to unphosphorylated GluA1. GAPDH was used as housekeeping protein. Data are expressed as percentage of saline group ( $\mathrm{n}=6-7 \mathrm{mice} /$ group). Data are presented as means \pm SEM and analyzed by one-way ANOVA followed by Tukey post-hoc comparisons post. ${ }^{*} p<0.01$ saline vs d-amph, \#\# $p<$ 0.01 saline vs. betaxolol. (b) Comparison of the expression level of BG-enriched transcripts between mice repeatedly administered with saline or d-amphetamine. All genes analyzed by qRT-PCR were normalized to Tbp2 $\alpha$. Data are presented as mean \pm SEM and analyzed by twosided $t$ test. ${ }^{*} p<0.05,{ }^{* * *} p<0.001$. (c) Same analyses as in (a) performed in methylphenidatetreated mice. Data are expressed as percentage of saline group $(n=6-7$ mice/group $)$. Data are presented as means \pm SEM and analyzed by one-way ANOVA followed by Tukey post-hoc comparisons post. $* * * p<0.001$ saline $v s$. d-amph, \#\#\# $p<0.001$ saline vs betaxolol. (d) Same analyses as in (c) performed in methylphenidate-treated mice. ${ }^{*} p<0.05$, ${ }^{* *} p<0.01$. For detailed statistics see Supplementary Table 4. 


\section{Supplemental Figure Legends}

Supplemental Figure 1. Ribotag methodology. Drawing illustrating the Ribotag methodology in the Gfap-RiboTag mice.

Supplemental Figure 2. Distribution of TH- and VMAT2-positive fibers in the cerebellum.

(a) Immunofluorescence for tyrosine hydroxylase ( $\mathrm{TH}$, cyan) in the cerebellar cortex. Note the lattice of TH-positive fibers present in both Purkinje (PC) and molecular layers (m.l). Scale bar: $30 \mu \mathrm{m}$. (b) Double immunofluorescence for VMAT2 (magenta) and GFAP (cyan). Note the dense VMAT2 immunoreactivity in the molecular layer. Scale bar: $15 \mu \mathrm{m}$. PCl: Purkinje cell layer; g.l: granular layer; m.l: molecular layer.

Supplemental Figure 3. Injection of the amber light-drivable channelrhodospinChrimson in the VTA of Slc6a3-Cre mice. Representative images of transduced DAT neurons expressing tdTomato (red). Scale bar: $500 \mu \mathrm{m}$.

Supplemental Figure 4. Transcriptional analysis in the cerebellum of VMAT2-cKO mice. Analysis of transcripts encoding glial cells (Gfap, Itgam, Aif1) including BGCs (Apq4, Kcnj10) and PC (Gria2) markers as well as transcripts encoding receptors (Drd2, Drd3, Adrb2, Adrala) transporters (Slc6a3), and enzymes involved in catecholamine biosynthesis $(D d c, T h)$ and degradation (Comt, Maoa, Maob) in control and VMAT2-cKO mice ( $\mathrm{n}=6-7$ mice / genotype). All genes were normalized to $\operatorname{Tb} p 2 \alpha$. Data are presented as mean \pm SEM and analyzed by twosided $t$ test. For detailed statistics see Supplementary Table 4. 


\section{Supplemental Figure 5. Transcripts encoding proteins involved in cAMP/PKA turnover}

enriched in BG. qRT-PCR analysis of $A d c y 2$, Pde $7 b$, Ppp $1 r 14 c$ and Ppmla transcripts in cerebellar extracts from Gfap-RiboTag mice after HA-immunoprecipitation. All genes were normalized to $\operatorname{Tbp} 2 \alpha$. Data are presented as the fold change comparing the pellet fraction versus the input $(\mathrm{n}=8-9$ pooled samples of 2 mice / pool). Data were analyzed by two-sided $t$ test. $* * * p<0.001$. For detailed statistics see Supplementary Table 4. 


\section{Supplementary Table 1}

\section{Mouse lines used in the study}

\begin{tabular}{lll}
\hline \hline Article's nomenclature (Mouse line) & Mouse strain & Citation \\
\hline \hline D1R-eGFP (Drdla-eGFP) & $\operatorname{Tg}($ Drd1-EGFP)X60Gsat/Mmmh & (Gong et al., 2003) \\
Dbh-Cre (Dbh-Cre) & $\operatorname{Tg}($ Dbh-cre)KH212Gsat/Mmucd & (Gong et al., 2003) \\
$\begin{array}{l}\text { VMAT2-cKO } \\
\text { (Dbh-Cre:Slc18a2-LoxP/LoxP) }\end{array}$ & (Isingrini et al., 2016) \\
Slc6a3-Cre (Slc6a3-Cre) & $\operatorname{Tg}($ Slc6a3-icre)1Fto & \\
$\begin{array}{l}\text { DAT-YFP } \\
\text { (Slc6a3-Cre:ROSA26-eYFP) }\end{array}$ & & (Turiault et al., 2007) \\
Gfap-RiboTag & & (Madisen et al., 2010) \\
(Gfap-CreERT2:RiboTag) & & (Mongrédien et al., 2019)
\end{tabular}




\section{Supplementary Table 2}

\section{List of Primary Antibodies}

\begin{tabular}{|c|c|c|c|}
\hline Antigen & Species & Dilution & Supplier/Catalog no./References) \\
\hline$\overline{\mathrm{HA}}$ & Mouse & $1: 1000$ (IF) & Biolegend (\#901502) \\
\hline HA & Rabbit & $1: 1000$ (IF) & Rockland (\#600-401-384) \\
\hline DARPP-32 & Rabbit & $1: 1000$ (IF) & Cell Signaling Technology (\#2306) \\
\hline GFP & Chicken & $1: 1000$ (IF) & Life Technologies (\#A10262) \\
\hline RFP & Rabbit & $1: 1000(\mathrm{IF})$ & MBL (\#PM005) \\
\hline RFP & Mouse & $1: 1000$ (IF) & MBL (\#M155-3) \\
\hline Parvalbumin & Mouse & $1: 1000$ (IF) & Millipore (MAB1572) \\
\hline $\mathrm{TH}$ & Rabbit & $1: 1000$ (IF) & Millipore (\#AB152) \\
\hline TH & Chicken & $1: 1000$ (IF) & Aves Labs \\
\hline GFAP & Chicken & $1: 1500$ (IF) & Abcam (\#ab4674) \\
\hline GFAP & Rabbit & $1: 1500$ (IF) & Dako (\#N1506) \\
\hline VMAT2 & Rabbit & $1: 1000$ (IF) & Synaptic System (\#138302) \\
\hline Iba1 & Rabbit & $1: 1000$ (IF) & Wako (\#019-19741) \\
\hline Calbindin-D28k & Mouse & $1: 1000$ (IF) & Swant (\#300) \\
\hline Calbindin-D28k & Rabbit & $1: 1000$ (IF) & Swant (\#CB38) \\
\hline EAAT1 (GLAST-1) & Rabbit & $1: 500$ (IF) & Abcam (\#ab416) \\
\hline NeuN & Mouse & $1: 1000$ (IF) & Millipore (\#MAB377) \\
\hline GluA1 & Rabbit & $1: 1000$ (IF); $1: 1000(\mathrm{WB})$ & Millipore (\#AB1504) \\
\hline pS845-GluA1 & Rabbit & $1: 1000(\mathrm{WB})$ & Millipore (\#04-1073) \\
\hline pS831-GluA1 & Rabbit & $1: 1000(\mathrm{WB})$ & Millipore (\#01-823) \\
\hline$\beta$-actin & Mouse & $1: 40000(\mathrm{WB})$ & Abcam (\#AB6276) \\
\hline GAPDH & Mouse & $1: 40000(\mathrm{WB})$ & Santa Cruz (\#SC-32233) \\
\hline
\end{tabular}




\section{Supplementary Table 3}

\section{Sequences of PCR primers}

\begin{tabular}{|c|c|c|}
\hline Gene & Primer forward & Primer reverse \\
\hline Gfap & AGCGAGCGTGCAGAGATGA & AGGAAGCGGACCTTCTCGAT \\
\hline S100b & TTCCACCAGTACTCCGGGCG & GCGACGAAGGCCATGAACTCC \\
\hline Vim & AGGCTGCCAACCGGAACAAC & GGCGGCCAATAGTGTCCTGG \\
\hline Slc1a3 & CATCGTGCTGACATCTGTGG & TCACCGAGTTCCCCATTTCA \\
\hline Lgi4 & GTTGGTGGCCGCTTCGAGAG & TGGAAGACATGGGACCCTCGG \\
\hline Dao & GGTCCGGCTAGAAAGAGAATGGC & CTCAGAGGTGGGAGGGAGGC \\
\hline Acsbg1 & GTGGGCCATTCTCCAACGTGAC & GGAAGATGCTTGCCGGGCTG \\
\hline Pcp2 & TGCAGGGCGATCGGATGGAGGAG & TGAGGGGTGAGCAGGGGTTGAGG \\
\hline Calb1 & AGGAAAGGAGCTGCAGAACT & CTCTCTGTCCATATTGATCCACA \\
\hline Neurod1 & GCAGCTCTGGAGCCCTTCTT & GCGGCACCGGAAGAGAAGAT \\
\hline Grm2 & CCATCTTCTACGTCACCTCC & AGGAACAAGCTGGGATCCAG \\
\hline Lypde6 & TGTATGAGTGACACGCCAGT & CTGCTGCTTTCTCACAGGTG \\
\hline Nos1ap & GCTGCAGAACAAAGACATGCTCCA & CTCTGGCTTAGGGGTGGTGGA \\
\hline Grp & GCACGGTCCTGGCTAAGATGTA & GCATACAGGGACGGGGATTCAT \\
\hline Acan & CTCGGGCAGAAGAAAGATCGCTAC & GGTCTCATGCTCCGCTTCTGTAG \\
\hline Aif1 & CCCCCAGCCAAGAAAGCTAT & GCCCCACCGTGTGACATC \\
\hline Cnp & GCTGCACTGTACAACCAAATTCTG & ACCTCCTGCTGGGCGTATT \\
\hline Gria1 & CGAGTTCTGCTACAAATCCCG & ACCACTCTGCCATTCTCTCC \\
\hline Drd1 & TCGAACTGTATGGTGCCCTT & TGGGGTTCAGGGAGGAATTC \\
\hline $\operatorname{Drd2}$ & CCTTCATCGTCACCCTGCTGG & CTCCATTTCCAGCTCCTGAG \\
\hline Drd3 & CGAGAGAAGAAGGCCACCCAG & ACGTAGCCAAGCCATGTCGT \\
\hline Slc6a3 & AGCATTGTGACCTTCAGACCCC & AGCTGGCGGTCTTTCTCAGG \\
\hline$D d c$ & ATCTTCGGCCCCTGATCCCT & GGTATGAGCTAGCCGTGGGG \\
\hline$T h$ & CCGTGCAGCCCTACCAAGAT & CCGGATGGTGTGAGGACTGTC \\
\hline Adrala & CTGCTGTGTGGGGTCGTCGA & ACTGGGTCTGTCTGTCGCACA \\
\hline Adrb1 & ACAACGACCCCAAGTGCTGC & CGCAGCTGTCGATCTTCTTTACCT \\
\hline Adrb2 & GCGCTCACCTGCTAACCTGC & CCAAACACGATGGCCAGGACG \\
\hline Adcy 2 & AGCTGGCGTCATAGGGGCTC & GGTCCCCTTTCCCCTTCACGT \\
\hline Pde 7b & GCTCCCTCATCTTGGCCACG & TCCACTGCTTGCTCATCTCCCA \\
\hline Ppp1r14c & CAGCAACAACGACGCCACCA & GCTCTTTCCTCCTCGCTGTTGG \\
\hline Ppm1a & TGGGACGTCATGGGGAACGA & TTCTTCACCGCCTCTGCCGA \\
\hline Comt & CCATCCTCATCGGGGCATCC & GGGTTCCCGGGACAATGACA \\
\hline Maoa & ACGGAAATTTGTAGGTGGCTCTGG & CCATGCACTTGATGACAGCCCC \\
\hline Maob & TGGTGGATCTGGTCAAGTGA & ACACGAGAGATCAGCTGGTT \\
\hline Itgam & ATGGTCACCTCCTGCTTGTGAG & CCAGCAGTGATGAGAGCCAAGA \\
\hline
\end{tabular}


bioRxiv preprint doi: https://doi.org/10.1101/2020.07.10.196766; this version posted July 10, 2020. The copyright holder for this preprint (which was not certified by peer review) is the author/funder, who has granted bioRxiv a license to display the preprint in perpetuity. It is made available under aCC-BY-NC-ND 4.0 International license.

\begin{tabular}{|l|l|l|}
\hline Gria2 & AGGCGAAACGAATGAAGGTG & CTTGCCTTGTTCCTCGTGG \\
\hline Apq4 & GCCGGCATCCTCTACCTGGT & TCCCTTTTGTCTGCTGCGCG \\
\hline Kcnj10 & TGCAGGCACGTGGTTCCTCT & CACCTGCACCACACAAGGCG \\
\hline
\end{tabular}


bioRxiv preprint doi: https://doi.org/10.1101/2020.07.10.196766; this version posted July 10,2020 . The copyright holder for this preprint (which was not certified by peer review) is the author/funder, who has granted bioRxiv a license to display the preprint in perpetuity. It is made available under aCC-BY-NC-ND 4.0 International license.

\section{Supplementary Table 4: Statistical analysis}

\begin{tabular}{|c|c|c|}
\hline Figures & Groups (n number of mice) & Statistical Analysis \\
\hline $1 \mathrm{e}$ & $\begin{array}{l}\text { Transcripts (input, pellet) } \\
\text { Gfap }:(\mathrm{n}=5, \mathrm{n}=5) \\
\text { S100b }:(\mathrm{n}=5, \mathrm{n}=5) \\
\text { Vim }:(\mathrm{n}=6, \mathrm{n}=5) \\
\text { Slc1a3 }:(\mathrm{n}=6, \mathrm{n}=5) \\
\text { Cdc42ep } 4:(\mathrm{n}=6, \mathrm{n}=5) \\
\text { Lgi4 }:(\mathrm{n}=6, \mathrm{n}=5) \\
\text { Dao }:(\mathrm{n}=6, \mathrm{n}=5) \\
\text { Acsbg1 }:(\mathrm{n}=6, \mathrm{n}=5) \\
\text { Pcp } 2:(\mathrm{n}=6, \mathrm{n}=5) \\
\text { Calb1 }:(\mathrm{n}=6, \mathrm{n}=5) \\
\text { Neurod1 }:(\mathrm{n}=6, \mathrm{n}=5) \\
\text { Grm } 2:(\mathrm{n}=6, \mathrm{n}=5) \\
\text { Lypd6 }:(\mathrm{n}=6, \mathrm{n}=5) \\
\text { Nos1ap }:(\mathrm{n}=6, \mathrm{n}=5) \\
\text { Grp }:(\mathrm{n}=6, \mathrm{n}=5) \\
\text { Acan }:(\mathrm{n}=6, \mathrm{n}=5) \\
\text { Aif1 }:(\mathrm{n}=6, \mathrm{n}=5) \\
\text { Copp }:(\mathrm{n}=6, \mathrm{n}=5) \\
\text { Gria1 }:(\mathrm{n}=6, \mathrm{n}=5)\end{array}$ & $\begin{array}{l}\text { Unpaired t-test } \\
\mathrm{t}_{8}=8.964, \mathrm{p}<0.0001 \\
\mathrm{t}_{8}=15.53, \mathrm{p}<0.0001 \\
\mathrm{t}_{9}=2.312, \mathrm{p}=0.046 \\
\mathrm{t}_{9}=5.051, \mathrm{p}<0.0007 \\
\mathrm{t}_{9}=9.398, \mathrm{p}<0.0001 \\
\mathrm{t}_{9}=13.38, \mathrm{p}<0.0001 \\
\mathrm{t}_{9}=20.00, \mathrm{p}<0.0001 \\
\mathrm{t}_{9}=9.435, \mathrm{p}<0.0001 \\
\mathrm{t}_{9}=4.098, \mathrm{p}=0.0027 \\
\mathrm{t}_{9}=9.685, \mathrm{p}<0.0001 \\
\mathrm{t}_{9}=15.18, \mathrm{p}<0.0001 \\
\mathrm{t}_{9}=13.40, \mathrm{p}<0.0007 \\
\mathrm{t}_{9}=15.18, \mathrm{p}<0.0001 \\
\mathrm{t}_{9}=6.646, \mathrm{p}<0.0001 \\
\mathrm{t}_{9}=7.561, \mathrm{p}<0.0001 \\
\mathrm{t}_{9}=5.669, \mathrm{p}=0.0003 \\
\mathrm{t}_{9}=6.578, \mathrm{p}=0.0001 \\
\mathrm{t}_{9}=3.275, \mathrm{p}=0.0096 \\
\mathrm{t}_{9}=8.822, \mathrm{p}<0.0001\end{array}$ \\
\hline $2 a$ & $\begin{array}{l}\text { Saline }(n=5) \\
\text { D-amphetamine }(n=5)\end{array}$ & $\begin{array}{l}\text { Unpaired t-test }(\mathrm{pS} 845-\mathrm{GluA} 1) \\
\text { Vermis: } \mathrm{t}_{8}=3.762, \mathrm{p}=0.0055 \\
\text { Lateral: } \mathrm{t}_{6}=3.811, \mathrm{p}=0.0089 \\
\text { Unpaired t-test (pS831-GluA1) } \\
\text { Vermis: } \mathrm{t}_{8}=0.4005, \mathrm{p}=0.69 \\
\text { Lateral: } \mathrm{t}_{8}=0.4376, \mathrm{p}=0.67\end{array}$ \\
\hline $2 b$ & $\begin{array}{l}\text { Saline }(n=4) \\
\text { D-amphetamine }(n=4)\end{array}$ & $\begin{array}{l}\text { Unpaired t-test } \\
\text { pS845-GluA1: } \mathrm{t}_{6}=2.649, \mathrm{p}=0.0381 \\
\text { pS831-GluA1: } \mathrm{t}_{6}=0.6776, \mathrm{p}=0.523\end{array}$ \\
\hline $2 \mathrm{c}$ & $\begin{array}{l}\text { Saline }(n=7) \\
\text { Methylphenidate }(n=7)\end{array}$ & $\begin{array}{l}\text { Unpaired } \mathrm{t} \text {-test } \\
\text { pS845-GluA1: } \mathrm{t}_{12}=2.124, \mathrm{p}=0.055 \\
\text { pS831-GluA1: } \mathrm{t}_{12}=2.624, \mathrm{p}=0.022\end{array}$ \\
\hline $3 c$ & $\begin{array}{l}\text { Transcripts (input, pellet) } \\
\text { Slc6a3 }:(\mathrm{n}=5, \mathrm{n}=5) \\
\text { Ddc }:(\mathrm{n}=5, \mathrm{n}=5) \\
\text { Th }:(\mathrm{n}=5, \mathrm{n}=5)\end{array}$ & $\begin{array}{l}\text { Unpaired t-test } \\
\mathrm{t}_{8}=8.437, \mathrm{p}<0.0001 \\
\mathrm{t}_{8}=1.060, \mathrm{p}=0.32 \\
\mathrm{t}_{8}=1.394, \mathrm{p}=0.207\end{array}$ \\
\hline
\end{tabular}




\begin{tabular}{|c|c|c|}
\hline $4 \mathrm{~b}$ & $\begin{array}{l}\text { Transcripts (input, pellet) } \\
\text { Drd1 }:(\mathrm{n}=5, \mathrm{n}=5) \\
\text { Drd2 }:(\mathrm{n}=5, \mathrm{n}=5) \\
\text { Drd3 }:(\mathrm{n}=4, \mathrm{n}=5)\end{array}$ & $\begin{array}{l}\text { Unpaired t-test } \\
\mathrm{t}_{8}=7.949, \mathrm{p}<0.0001 \\
\mathrm{t}_{8}=0.4887, \mathrm{p}=0.638 \\
\mathrm{t}_{7}=0.02035, \mathrm{p}=0.98\end{array}$ \\
\hline $4 c$ & $\begin{array}{l}\text { Saline-Saline }(n=5) \\
\text { Saline-D-amphetamine }(n=6) \\
\text { SCH23390-Saline }(n=6) \\
\text { SCH23390- D-amphetamine }(n=6)\end{array}$ & $\begin{array}{l}\text { One-way ANOVA } \\
\mathrm{F}_{(3,19)}=11.62, \mathrm{p}=0.0001\end{array}$ \\
\hline $4 d$ & $\begin{array}{l}\text { Saline }(n=6) \\
\text { Cocaine }(n=6) \\
\text { GBR12783 }(n=6)\end{array}$ & $\begin{array}{l}\text { One-way ANOVA } \\
\mathrm{F}_{(2,15)}=0.9, \mathrm{p}=0.4143\end{array}$ \\
\hline $5 c$ & $\begin{array}{l}\text { Transcripts (control, VMAT2-cKO) } \\
\text { Gria1 }:(\mathrm{n}=7, \mathrm{n}=7) \\
\text { Drd1 }:(\mathrm{n}=6, \mathrm{n}=7) \\
\text { Adrb1 }:(\mathrm{n}=7, \mathrm{n}=7)\end{array}$ & $\begin{array}{l}\text { Unpaired t-test } \\
\mathrm{t}_{12}=0.8588, \mathrm{p}=0.407 \\
\mathrm{t}_{11}=1.428, \mathrm{p}=0.181 \\
\mathrm{t}_{12}=1.057, \mathrm{p}=0.311\end{array}$ \\
\hline $5 d$ & $\begin{array}{l}\text { Control Saline }(\mathrm{n}=7) \\
\text { Control D-amphetamine }(\mathrm{n}=7) \\
\text { VMAT2-cKO Saline }(\mathrm{n}=7) \\
\text { VMAT2-cKO D-amphetamine }(\mathrm{n}=6)\end{array}$ & $\begin{array}{l}\text { Two-way ANOVA } \\
\text { Genotype } F_{(1,23)}=9.354, p=0.0054 \\
\text { Treatment } F_{(1,23)}=24.03, p<0.0001 \\
\text { Interaction } F_{(1,23)}=14.88, p=0.0008\end{array}$ \\
\hline $5 \mathrm{e}$ & $\begin{array}{l}\text { Transcripts (input, pellet) } \\
\text { Adra1a }:(\mathrm{n}=6, \mathrm{n}=5) \\
\text { Adrb1 }:(\mathrm{n}=6, \mathrm{n}=5) \\
\text { Adrb2 }:(\mathrm{n}=5, \mathrm{n}=5)\end{array}$ & $\begin{array}{l}\text { Unpaired t-test } \\
\mathrm{t}_{9}=8.176, \mathrm{p}<0.0001 \\
\mathrm{t}_{9}=9.276, \mathrm{p}<0.0001 \\
\mathrm{t}_{8}=0.6044, \mathrm{p}=0.567\end{array}$ \\
\hline $5 \mathrm{~g}$ & $\begin{array}{l}\text { Saline-Saline }(\mathrm{n}=5) \\
\text { Saline-D-amphetamine }(\mathrm{n}=6) \\
\text { Propranolol-Saline }(\mathrm{n}=5) \\
\text { Propranolol-D-amphetamine }(\mathrm{n}=6) \\
\text { Betaxolol-Saline }(\mathrm{n}=5) \\
\text { Betaxolol-D-amphetamine }(\mathrm{n}=6)\end{array}$ & $\begin{array}{l}\text { One-way ANOVA } \\
\mathrm{F}_{(5,27)}=8.904, \mathrm{p}<0.0001\end{array}$ \\
\hline $6 a$ & $\begin{array}{l}\text { Saline-Saline }(n=7) \\
\text { Saline-D-amphetamine }(n=7) \\
\text { Betaxolol-Saline }(n=6) \\
\text { Betaxolol-D-amphetamine }(n=7)\end{array}$ & $\begin{array}{l}\text { One-way ANOVA } \\
\mathrm{F}_{(3,23)}=8.128, \mathrm{p}=0.0007\end{array}$ \\
\hline $6 b$ & $\begin{array}{l}\text { Transcripts (saline, d-amphetamine) } \\
\text { Adrb1 }:(\mathrm{n}=6, \mathrm{n}=7) \\
\text { Adcy }:(\mathrm{n}=10, \mathrm{n}=9) \\
\text { Ppp1r14c }:(\mathrm{n}=10, \mathrm{n}=9) \\
\text { Ppm1a }:(\mathrm{n}=10, \mathrm{n}=8) \\
\text { Pde } 7 b:(\mathrm{n}=10, \mathrm{n}=9)\end{array}$ & $\begin{array}{l}\text { Unpaired t-test } \\
\mathrm{t}_{11}=3.013, \mathrm{p}=0.0118 \\
\mathrm{t}_{17}=2.347, \mathrm{p}=0.03 \\
\mathrm{t}_{17}=5.203, \mathrm{p}<0.0001 \\
\mathrm{t}_{16}=2.228, \mathrm{p}=0.04 \\
\mathrm{t}_{17}=1.591, \mathrm{p}=0.13\end{array}$ \\
\hline $6 c$ & $\begin{array}{l}\text { Saline-Saline }(\mathrm{n}=7) \\
\text { Saline-Methylphenidate }(\mathrm{n}=7) \\
\text { Betaxolol-Saline }(\mathrm{n}=7) \\
\text { Betaxolol-Methylphenidate }(\mathrm{n}=7)\end{array}$ & $\begin{array}{l}\text { One-way ANOVA } \\
\mathrm{F}_{(3,24)}=23.71, \mathrm{p}<0.0001\end{array}$ \\
\hline $6 \mathrm{~d}$ & $\begin{array}{l}\text { Transcripts (saline, methylphenidate) } \\
\text { Adrb1 }:(\mathrm{n}=10, \mathrm{n}=10) \\
\operatorname{Adcy} 2:(\mathrm{n}=10, \mathrm{n}=9) \\
\text { Ppp1r14c }:(\mathrm{n}=10, \mathrm{n}=8)\end{array}$ & $\begin{array}{l}\text { Unpaired t-test } \\
\mathrm{t}_{18}=2.216, \mathrm{p}=0.047 \\
\mathrm{t}_{17}=2.809, \mathrm{p}=0.0121 \\
\mathrm{t}_{16}=3,552, \mathrm{p}=0.0027\end{array}$ \\
\hline
\end{tabular}




\begin{tabular}{|c|c|c|}
\hline & $\begin{array}{l}\text { Ppm1a }:(\mathrm{n}=10, \mathrm{n}=8) \\
\text { Pde7b }:(\mathrm{n}=10, \mathrm{n}=8)\end{array}$ & $\begin{array}{l}\mathrm{t}_{16}=2.858, \mathrm{p}=0.0114 \\
\mathrm{t}_{16}=3.708, \mathrm{p}=0.0019\end{array}$ \\
\hline $\mathrm{S} 4$ & $\begin{array}{l}\text { Transcripts (control, VMAT2-cKO) } \\
\text { Adrb2 }:(\mathrm{n}=7, \mathrm{n}=7) \\
\text { Adra1a }:(\mathrm{n}=7, \mathrm{n}=7) \\
\text { Ddc }:(\mathrm{n}=6, \mathrm{n}=7) \\
\text { Th }:(\mathrm{n}=6, \mathrm{n}=6) \\
\text { Drd3 }:(\mathrm{n}=6, \mathrm{n}=6) \\
\text { Comt }:(\mathrm{n}=7, \mathrm{n}=7) \\
\text { Maoa }:(\mathrm{n}=7, \mathrm{n}=7) \\
\text { Maob }:(\mathrm{n}=7, \mathrm{n}=7) \\
\text { Drd2 }:(\mathrm{n}=7, \mathrm{n}=7) \\
\text { Slc6a3 }:(\mathrm{n}=6, \mathrm{n}=6) \\
\text { Gfap }:(\mathrm{n}=7, \mathrm{n}=7) \\
\text { Itgam }:(\mathrm{n}=7, \mathrm{n}=7) \\
\text { Aif1 }:(\mathrm{n}=7, \mathrm{n}=7) \\
\text { Apq4 }:(\mathrm{n}=7, \mathrm{n}=7) \\
\text { Kcnj10 }:(\mathrm{n}=7, \mathrm{n}=7) \\
\text { Gria2 }:(\mathrm{n}=7, \mathrm{n}=7)\end{array}$ & $\begin{array}{l}\text { Unpaired t-test } \\
\mathrm{t}_{12}=0.4212, \mathrm{p}=0.68 \\
\mathrm{t}_{12}=0.7538, \mathrm{p}=0.465 \\
\mathrm{t}_{11}=0.1486, \mathrm{p}=0.884 \\
\mathrm{t}_{10}=1.306, \mathrm{p}=0.228 \\
\mathrm{t}_{10}=0.8116, \mathrm{p}=0.436 \\
\mathrm{t}_{12}=1.204, \mathrm{p}=0.25 \\
\mathrm{t}_{12}=0.1638, \mathrm{p}=0.872 \\
\mathrm{t}_{12}=1.151, \mathrm{p}=0.27 \\
\mathrm{t}_{12}=0.1923, \mathrm{p}=0.85 \\
\mathrm{t}_{10}=1.970, \mathrm{p}=0.077 \\
\mathrm{t}_{12}=1.149, \mathrm{p}=0.162 \\
\mathrm{t}_{12}=0.296, \mathrm{p}=0.7718 \\
\mathrm{t}_{12}=0.416, \mathrm{p}=0.684 \\
\mathrm{t}_{12}=0.208, \mathrm{p}=0.838 \\
\mathrm{t}_{12}=0.6828, \mathrm{p}=0.507 \\
\mathrm{t}_{12}=0.961, \mathrm{p}=0.355\end{array}$ \\
\hline S5 & $\begin{array}{l}\text { Transcripts (input, pellet) } \\
\text { Ppp1r14c: }(\mathrm{n}=9, \mathrm{n}=8) \\
\text { Ppm1a }:(\mathrm{n}=9, \mathrm{n}=8) \\
\text { Pde } 7 b:(\mathrm{n}=9, \mathrm{n}=8) \\
\text { Adcy } 2:(\mathrm{n}=9, \mathrm{n}=8)\end{array}$ & $\begin{array}{l}\text { Unpaired t-test } \\
\mathrm{t}_{15}=8.638, \mathrm{p}<0.0001 \\
\mathrm{t}_{15}=0.1095, \mathrm{p}=0.9143 \\
\mathrm{t}_{15}=6.254, \mathrm{p}<0.0001 \\
\mathrm{t}_{15}=13.02, \mathrm{p}<0.0001\end{array}$ \\
\hline
\end{tabular}




\section{REFERENCES}

Biever, A., Puighermanal, E., Nishi, A., David, A., Panciatici, C., Longueville, S., Xirodimas, D., Gangarossa, G., Meyuhas, O., Hervé, D., et al. (2015). PKA-dependent phosphorylation of ribosomal protein S6 does not correlate with translation efficiency in striatonigral and striatopallidal medium-sized spiny neurons. The Journal of neuroscience : the official journal of the Society for Neuroscience 35, 4113-4130.

Bledsoe, J., Semrud-Clikeman, M., and Pliszka, S.R. (2009). A magnetic resonance imaging study of the cerebellar vermis in chronically treated and treatment-naïve children with attentiondeficit/hyperactivity disorder combined type. Biological psychiatry 65, 620-624.

Burnashev, N., Khodorova, A., Jonas, P., Helm, P.J., Wisden, W., Monyer, H., Seeburg, P.H., and Sakmann, B. (1992). Calcium-permeable AMPA-kainate receptors in fusiform cerebellar glial cells. Science (New York, NY) 256, 1566-1570.

Camps, M., Kelly, P.H., and Palacios, J.M. (1990). Autoradiographic localization of dopamine D 1 and D 2 receptors in the brain of several mammalian species. Journal of neural transmission General section 80, 105-127.

Castellanos, F.X., Lee, P.P., Sharp, W., Jeffries, N.O., Greenstein, D.K., Clasen, L.S., Blumenthal, J.D., James, R.S., Ebens, C.L., Walter, J.M., et al. (2002). Developmental trajectories of brain volume abnormalities in children and adolescents with attentiondeficit/hyperactivity disorder. Jama 288, 1740-1748.

Ceolin, L., Bouquier, N., Vitre-Boubaker, J., Rialle, S., Severac, D., Valjent, E., Perroy, J., and Puighermanal, E. (2017). Cell Type-Specific mRNA Dysregulation in Hippocampal CA1 Pyramidal Neurons of the Fragile X Syndrome Mouse Model. Frontiers in molecular neuroscience 10,340 .

Choi, K.H., Edwards, S., Graham, D.L., Larson, E.B., Whisler, K.N., Simmons, D., Friedman, A.K., Walsh, J.J., Rahman, Z., Monteggia, L.M., et al. (2011). Reinforcement-related regulation of AMPA glutamate receptor subunits in the ventral tegmental area enhances motivation for cocaine. The Journal of neuroscience : the official journal of the Society for Neuroscience 31, 7927-7937.

Chrapusta, S.J., Egan, M.F., Masserano, J.M., and Wyatt, R.J. (1994). Dopamine release in the rat cerebellum and hippocampus: a tissue 3-methoxytyramine study. Brain research 655, 271275.

Corkrum, M., Covelo, A., Lines, J., Bellocchio, L., Pisansky, M., Loke, K., Quintana, R., Rothwell, P.E., Lujan, R., Marsicano, G., et al. (2020). Dopamine-Evoked Synaptic Regulation in the Nucleus Accumbens Requires Astrocyte Activity. Neuron 105, 1036-1047.e1035.

De Zeeuw, C.I., and Hoogland, T.M. (2015). Reappraisal of Bergmann glial cells as modulators of cerebellar circuit function. Frontiers in cellular neuroscience 9, 246.

Douyard, J., Shen, L., Huganir, R.L., and Rubio, M.E. (2007). Differential neuronal and glial expression of GluR1 AMPA receptor subunit and the scaffolding proteins SAP97 and 4.1N during rat cerebellar development. The Journal of comparative neurology 502, 141-156.

Doyle, J.P., Dougherty, J.D., Heiman, M., Schmidt, E.F., Stevens, T.R., Ma, G., Bupp, S., Shrestha, P., Shah, R.D., Doughty, M.L., et al. (2008). Application of a translational profiling approach for the comparative analysis of CNS cell types. Cell 135, 749-762. 
Engert, V., and Pruessner, J.C. (2008). Dopaminergic and noradrenergic contributions to functionality in ADHD: the role of methylphenidate. Current neuropharmacology 6, 322-328.

Ferrario, C.R., Loweth, J.A., Milovanovic, M., Ford, K.A., Galiñanes, G.L., Heng, L.J., Tseng, K.Y., and Wolf, M.E. (2011). Alterations in AMPA receptor subunits and TARPs in the rat nucleus accumbens related to the formation of $\mathrm{Ca}^{2+}$-permeable AMPA receptors during the incubation of cocaine craving. Neuropharmacology 61, 1141-1151.

Franklin, K., and Paxinos, G. (2008). The Mouse Brain in Stereotaxic Coordinates, 3rd edn (Academic Press ).

Freedman, R., and Marwaha, J. (1980). Effects of acute and chronic amphetamine treatment on Purkinje neuron discharge in rat cerebellum. The Journal of pharmacology and experimental therapeutics 212, 390-396.

Gatley, S.J., Pan, D., Chen, R., Chaturvedi, G., and Ding, Y.S. (1996). Affinities of methylphenidate derivatives for dopamine, norepinephrine and serotonin transporters. Life sciences 58, 231-239.

Gelinas, J.N., Tenorio, G., Lemon, N., Abel, T., and Nguyen, P.V. (2008). Beta-adrenergic receptor activation during distinct patterns of stimulation critically modulates the PKAdependence of LTP in the mouse hippocampus. Learning \& memory (Cold Spring Harbor, NY) $15,281-289$.

Glaser, P.E., Surgener, S.P., Grondin, R., Gash, C.R., Palmer, M., Castellanos, F.X., and Gerhardt, G.A. (2006). Cerebellar neurotransmission in attention-deficit/hyperactivity disorder: does dopamine neurotransmission occur in the cerebellar vermis? Journal of neuroscience methods 151, 62-67.

Goldstein, L.B., and Macmillan, V. (1993). Acute unilateral sensorimotor cortex injury in the rat blocks d-amphetamine induced norepinephrine release in cerebellum. Restorative neurology and neuroscience 5, 371-376.

Gong, S., Zheng, C., Doughty, M.L., Losos, K., Didkovsky, N., Schambra, U.B., Nowak, N.J., Joyner, A., Leblanc, G., Hatten, M.E., et al. (2003). A gene expression atlas of the central nervous system based on bacterial artificial chromosomes. Nature 425, 917-925.

Guillem, A.M., Martínez-Lozada, Z., Hernández-Kelly, L.C., López-Bayghen, E., LópezBayghen, B., Calleros, O.A., Campuzano, M.R., and Ortega, A. (2015). Methylphenidate Increases Glutamate Uptake in Bergmann Glial Cells. Neurochemical research 40, 2317-2324.

Hu, H., Real, E., Takamiya, K., Kang, M.G., Ledoux, J., Huganir, R.L., and Malinow, R. (2007). Emotion enhances learning via norepinephrine regulation of AMPA-receptor trafficking. Cell 131, 160-173.

Ikai, Y., Takada, M., and Mizuno, N. (1994). Single neurons in the ventral tegmental area that project to both the cerebral and cerebellar cortical areas by way of axon collaterals. Neuroscience 61, 925-934.

Ikai, Y., Takada, M., Shinonaga, Y., and Mizuno, N. (1992). Dopaminergic and nondopaminergic neurons in the ventral tegmental area of the rat project, respectively, to the cerebellar cortex and deep cerebellar nuclei. Neuroscience 51, 719-728.

Isingrini, E., Perret, L., Rainer, Q., Amilhon, B., Guma, E., Tanti, A., Martin, G., Robinson, J., Moquin, L., Marti, F., et al. (2016). Resilience to chronic stress is mediated by noradrenergic regulation of dopamine neurons. Nature neuroscience 19, 560-563. 
Ivanov, I., Murrough, J.W., Bansal, R., Hao, X., and Peterson, B.S. (2014). Cerebellar morphology and the effects of stimulant medications in youths with attention deficithyperactivity disorder. Neuropsychopharmacology : official publication of the American College of Neuropsychopharmacology 39, 718-726.

Juorio, A.V., Li, X.M., Walz, W., and Paterson, I.A. (1993). Decarboxylation of L-dopa by cultured mouse astrocytes. Brain research 626, 306-309.

Koirala, S., and Corfas, G. (2010). Identification of novel glial genes by single-cell transcriptional profiling of Bergmann glial cells from mouse cerebellum. PloS one 5, e9198.

Krobert, K.A., Sutton, R.L., and Feeney, D.M. (1994). Spontaneous and amphetamine-evoked release of cerebellar noradrenaline after sensorimotor cortex contusion: an in vivo microdialysis study in the awake rat. Journal of neurochemistry 62, 2233-2240.

Kuczenski, R., and Segal, D.S. (1997). Effects of methylphenidate on extracellular dopamine, serotonin, and norepinephrine: comparison with amphetamine. Journal of neurochemistry 68 , 2032-2037.

Kuczenski, R., Segal, D.S., and Todd, P.K. (1997). Behavioral sensitization and extracellular dopamine responses to amphetamine after various treatments. Psychopharmacology 134, 221 229.

Lakhan, S.E., and Kirchgessner, A. (2012). Prescription stimulants in individuals with and without attention deficit hyperactivity disorder: misuse, cognitive impact, and adverse effects. Brain and behavior 2, 661-677.

Li, D., Herrera, S., Bubula, N., Nikitina, E., Palmer, A.A., Hanck, D.A., Loweth, J.A., and Vezina, P. (2011). Casein kinase 1 enables nucleus accumbens amphetamine-induced locomotion by regulating AMPA receptor phosphorylation. Journal of neurochemistry 118 , 237-247.

Li, X.M., Juorio, A.V., Paterson, I.A., Walz, W., Zhu, M.Y., and Boulton, A.A. (1992). Gene expression of aromatic L-amino acid decarboxylase in cultured rat glial cells. Journal of neurochemistry $59,1172-1175$.

Longone, P., Impagnatiello, F., Mienville, J.M., Costa, E., and Guidotti, A. (1998). Changes in AMPA receptor-spliced variant expression and shift in AMPA receptor spontaneous desensitization pharmacology during cerebellar granule cell maturation in vitro. Journal of molecular neuroscience : MN 11, 23-41.

Madisen, L., Zwingman, T.A., Sunkin, S.M., Oh, S.W., Zariwala, H.A., Gu, H., Ng, L.L., Palmiter, R.D., Hawrylycz, M.J., Jones, A.R., et al. (2010). A robust and high-throughput Cre reporting and characterization system for the whole mouse brain. Nature neuroscience 13, 133 140 .

Maguire, M.E., Ross, E.M., and Gilman, A.G. (1977). beta-Adrenergic receptor: ligand binding properties and the interaction with adenylyl cyclase. Advances in cyclic nucleotide research 8 , $1-83$.

Mammen, A.L., Kameyama, K., Roche, K.W., and Huganir, R.L. (1997). Phosphorylation of the alpha-amino-3-hydroxy-5-methylisoxazole4-propionic acid receptor GluR1 subunit by calcium/calmodulin-dependent kinase II. The Journal of biological chemistry 272, 3252832533. 
Mao, L.M., Diaz, J.A., Fibuch, E.E., and Wang, J.Q. (2013). Regulation of phosphorylation of synaptic and extrasynaptic GluA1 AMPA receptors in the rat forebrain by amphetamine. European journal of pharmacology 715, 164-171.

Mao, L.M., Xue, B., Jin, D.Z., and Wang, J.Q. (2015). Dynamic increases in AMPA receptor phosphorylation in the rat hippocampus in response to amphetamine. Journal of neurochemistry 133, 795-805.

Martin, L.J., Blackstone, C.D., Levey, A.I., Huganir, R.L., and Price, D.L. (1993). AMPA glutamate receptor subunits are differentially distributed in rat brain. Neuroscience 53, 327358.

Matsui, K., Jahr, C.E., and Rubio, M.E. (2005). High-concentration rapid transients of glutamate mediate neural-glial communication via ectopic release. The Journal of neuroscience : the official journal of the Society for Neuroscience 25, 7538-7547.

Melchitzky, D.S., and Lewis, D.A. (2000). Tyrosine hydroxylase- and dopamine transporterimmunoreactive axons in the primate cerebellum. Evidence for a lobular- and laminar-specific dopamine innervation. Neuropsychopharmacology : official publication of the American College of Neuropsychopharmacology 22, 466-472.

Mongrédien, R., Erdozain, A.M., Dumas, S., Cutando, L., Del Moral, A.N., Puighermanal, E., Rezai Amin, S., Giros, B., Valjent, E., Meana, J.J., et al. (2019). Cartography of hevinexpressing cells in the adult brain reveals prominent expression in astrocytes and parvalbumin neurons. Brain structure \& function 224, 1219-1244.

Nelson, T.E., King, J.S., and Bishop, G.A. (1997). Distribution of tyrosine hydroxylaseimmunoreactive afferents to the cerebellum differs between species. The Journal of comparative neurology 379, 443-454.

Oe, Y., Wang, X., Patriarchi, T., Konno, A., Ozawa, K., Yahagi, K., Hirai, H., Tsuboi, T., Kitaguchi, T., Tian, L., et al. (2020). Distinct temporal integration of noradrenaline signaling by astrocytic second messengers during vigilance. Nature communications 11, 471.

Ozaita, A., Puighermanal, E., and Maldonado, R. (2007). Regulation of PI3K/Akt/GSK-3 pathway by cannabinoids in the brain. Journal of neurochemistry 102, 1105-1114.

Panagopoulos, N.T., Papadopoulos, G.C., and Matsokis, N.A. (1991). Dopaminergic innervation and binding in the rat cerebellum. Neuroscience letters 130, 208-212.

Pascoli, V., Terrier, J., Hiver, A., and Lüscher, C. (2015). Sufficiency of Mesolimbic Dopamine Neuron Stimulation for the Progression to Addiction. Neuron 88, 1054-1066.

Pascoli, V., Valjent, E., Corbillé, A.G., Corvol, J.C., Tassin, J.P., Girault, J.A., and Hervé, D. (2005). cAMP and extracellular signal-regulated kinase signaling in response to d-amphetamine and methylphenidate in the prefrontal cortex in vivo: role of beta 1-adrenoceptors. Molecular pharmacology 68, 421-429.

Paukert, M., Agarwal, A., Cha, J., Doze, V.A., Kang, J.U., and Bergles, D.E. (2014). Norepinephrine controls astroglial responsiveness to local circuit activity. Neuron 82, 1263 1270 .

Petralia, R.S., and Wenthold, R.J. (1992). Light and electron immunocytochemical localization of AMPA-selective glutamate receptors in the rat brain. The Journal of comparative neurology 318, 329-354. 
Pierce, R.C., and Kalivas, P.W. (1997). Repeated cocaine modifies the mechanism by which amphetamine releases dopamine. The Journal of neuroscience : the official journal of the Society for Neuroscience 17, 3254-3261.

Quansah, E., Ruiz-Rodado, V., Grootveld, M., and Zetterström, T.S.C. (2018). Methylphenidate alters monoaminergic and metabolic pathways in the cerebellum of adolescent rats. European neuropsychopharmacology : the journal of the European College of Neuropsychopharmacology 28, 513-528.

Roche, K.W., O'Brien, R.J., Mammen, A.L., Bernhardt, J., and Huganir, R.L. (1996). Characterization of multiple phosphorylation sites on the AMPA receptor GluR1 subunit. Neuron 16, 1179-1188.

Roche, K.W., Tingley, W.G., and Huganir, R.L. (1994). Glutamate receptor phosphorylation and synaptic plasticity. Current opinion in neurobiology 4, 383-388.

Rubia, K., Halari, R., Cubillo, A., Mohammad, A.M., Brammer, M., and Taylor, E. (2009). Methylphenidate normalises activation and functional connectivity deficits in attention and motivation networks in medication-naïve children with ADHD during a rewarded continuous performance task. Neuropharmacology 57, 640-652.

Saab, A.S., Neumeyer, A., Jahn, H.M., Cupido, A., Šimek, A.A., Boele, H.J., Scheller, A., Le Meur, K., Götz, M., Monyer, H., et al. (2012). Bergmann glial AMPA receptors are required for fine motor coordination. Science (New York, NY) 337, 749-753.

Saigal, R.P., Karamanlidis, A.N., Voogd, J., Michaloudi, H., and Mangana, O. (1980). Cerebellar afferents from motor nuclei of cranial nerves, the nucleus of the solitary tract, and nuclei coeruleus and parabrachialis in sheep, demonstrated with retrograde transport of horseradish peroxidase. Brain research 197, 200-206.

Saint-Mleux, B., Eggermann, E., Bisetti, A., Bayer, L., Machard, D., Jones, B.E., Mühlethaler, M., and Serafin, M. (2004). Nicotinic enhancement of the noradrenergic inhibition of sleeppromoting neurons in the ventrolateral preoptic area. The Journal of neuroscience : the official journal of the Society for Neuroscience 24, 63-67.

Salm, A.K., and McCarthy, K.D. (1992). The evidence for astrocytes as a target for central noradrenergic activity: expression of adrenergic receptors. Brain research bulletin 29, 265-275.

Savasta, M., Dubois, A., and Scatton, B. (1986). Autoradiographic localization of D1 dopamine receptors in the rat brain with [3H]SCH 23390. Brain research 375, 291-301.

Serulle, Y., Zhang, S., Ninan, I., Puzzo, D., McCarthy, M., Khatri, L., Arancio, O., and Ziff, E.B. (2007). A GluR1-cGKII interaction regulates AMPA receptor trafficking. Neuron 56, 670688.

Snyder, G.L., Allen, P.B., Fienberg, A.A., Valle, C.G., Huganir, R.L., Nairn, A.C., and Greengard, P. (2000). Regulation of phosphorylation of the GluR1 AMPA receptor in the neostriatum by dopamine and psychostimulants in vivo. The Journal of neuroscience : the official journal of the Society for Neuroscience 20, 4480-4488.

Sorensen, S.M., Hattox, S., Johnson, S.W., Bickford, P., Murphy, R., and Freedman, R. (1985). Norepinephrine-dependent and independent mechanisms of persistent effects of amphetamine in rat cerebellum. Life sciences 36, 2383-2389.

Sorensen, S.M., Johnson, S.W., and Freedman, R. (1982). Persistent effects of amphetamine on cerebellar Purkinje neurons following chronic administration. Brain research 247, 365-371. 
Stoodley, C.J. (2016). The Cerebellum and Neurodevelopmental Disorders. Cerebellum (London, England) 15, 34-37.

Sulzer, D., Chen, T.K., Lau, Y.Y., Kristensen, H., Rayport, S., and Ewing, A. (1995). Amphetamine redistributes dopamine from synaptic vesicles to the cytosol and promotes reverse transport. The Journal of neuroscience : the official journal of the Society for Neuroscience 15, 4102-4108.

Tenorio, G., Connor, S.A., Guévremont, D., Abraham, W.C., Williams, J., O'Dell, T.J., and Nguyen, P.V. (2010). 'Silent' priming of translation-dependent LTP by ß-adrenergic receptors involves phosphorylation and recruitment of AMPA receptors. Learning \& memory (Cold Spring Harbor, NY) 17, 627-638.

Turiault, M., Parnaudeau, S., Milet, A., Parlato, R., Rouzeau, J.D., Lazar, M., and Tronche, F. (2007). Analysis of dopamine transporter gene expression pattern -- generation of DAT-iCre transgenic mice. The FEBS journal 274, 3568-3577.

Valjent, E., Bertran-Gonzalez, J., Aubier, B., Greengard, P., Hervé, D., and Girault, J.A. (2010). Mechanisms of locomotor sensitization to drugs of abuse in a two-injection protocol. Neuropsychopharmacology : official publication of the American College of Neuropsychopharmacology 35, 401-415.

Valjent, E., Pagès, C., Hervé, D., Girault, J.A., and Caboche, J. (2004). Addictive and nonaddictive drugs induce distinct and specific patterns of ERK activation in mouse brain. The European journal of neuroscience 19, 1826-1836.

Valjent, E., Pascoli, V., Svenningsson, P., Paul, S., Enslen, H., Corvol, J.C., Stipanovich, A., Caboche, J., Lombroso, P.J., Nairn, A.C., et al. (2005). Regulation of a protein phosphatase cascade allows convergent dopamine and glutamate signals to activate ERK in the striatum. Proceedings of the National Academy of Sciences of the United States of America 102, 491496.

Volkow, N.D., Wang, G.J., Fowler, J.S., Hitzemann, R., Gatley, J., Ding, Y.S., Wong, C., and Pappas, N. (1998). Differences in regional brain metabolic responses between single and repeated doses of methylphenidate. Psychiatry research 83, 29-36.

Volkow, N.D., Wang, G.J., Fowler, J.S., Logan, J., Gatley, S.J., Hitzemann, R., Chen, A.D., Dewey, S.L., and Pappas, N. (1997). Decreased striatal dopaminergic responsiveness in detoxified cocaine-dependent subjects. Nature 386, 830-833.

Wang, J.Q., Arora, A., Yang, L., Parelkar, N.K., Zhang, G., Liu, X., Choe, E.S., and Mao, L. (2005). Phosphorylation of AMPA receptors: mechanisms and synaptic plasticity. Molecular neurobiology 32, 237-249.

Weyandt, L.L., Oster, D.R., Marraccini, M.E., Gudmundsdottir, B.G., Munro, B.A., Rathkey, E.S., and McCallum, A. (2016). Prescription stimulant medication misuse: Where are we and where do we go from here? Experimental and clinical psychopharmacology 24, 400-414.

White, F.J., and Kalivas, P.W. (1998). Neuroadaptations involved in amphetamine and cocaine addiction. Drug and alcohol dependence 51, 141-153.

Wilens, T.E., and Spencer, T.J. (2010). Understanding attention-deficit/hyperactivity disorder from childhood to adulthood. Postgraduate medicine 122, 97-109.

Wilens, T.E., Spencer, T.J., and Biederman, J. (2002). A review of the pharmacotherapy of adults with attention-deficit/hyperactivity disorder. Journal of attention disorders 5, 189-202. 
Xue, B., Edwards, M.C., Mao, L.M., Guo, M.L., Jin, D.Z., Fibuch, E.E., and Wang, J.Q. (2014). Rapid and sustained GluA1 S845 phosphorylation in synaptic and extrasynaptic locations in the rat forebrain following amphetamine administration. Neurochemistry international 64,48 54. 
bioRxiv preprint doi: https://doi.org/10.1101/2020.07.10.196766; this version posted July 10, 2020. The copyright holder for this preprint (which was not certified by peer review) is the author/funder, who has granted bioRxiv a license to display the preprint in perpetuity. It is made available under aCC-BY-NC-ND 4.0 International license.

\section{Cutando et al., Figure 1}
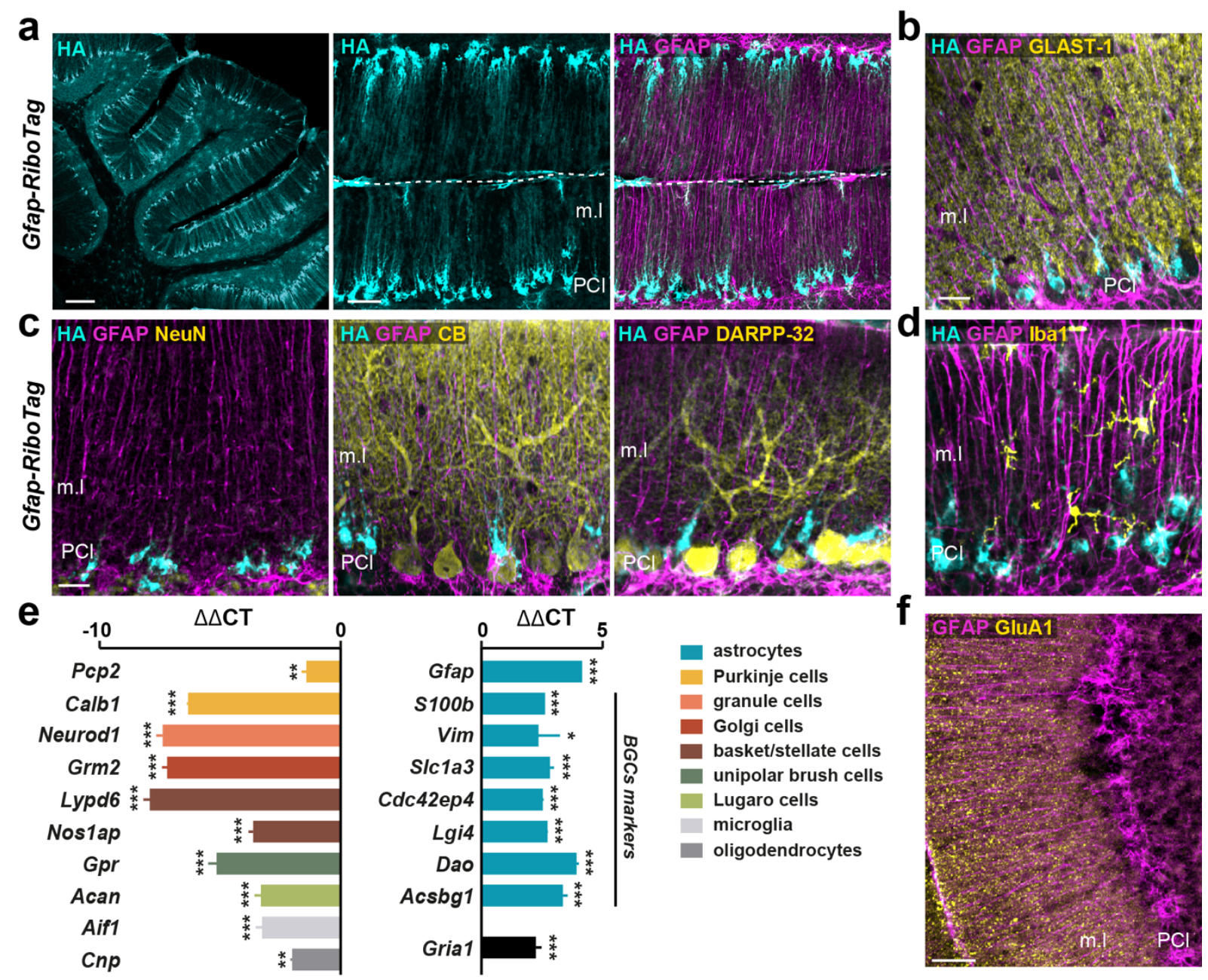


\section{Cutando et al., Figure 2}

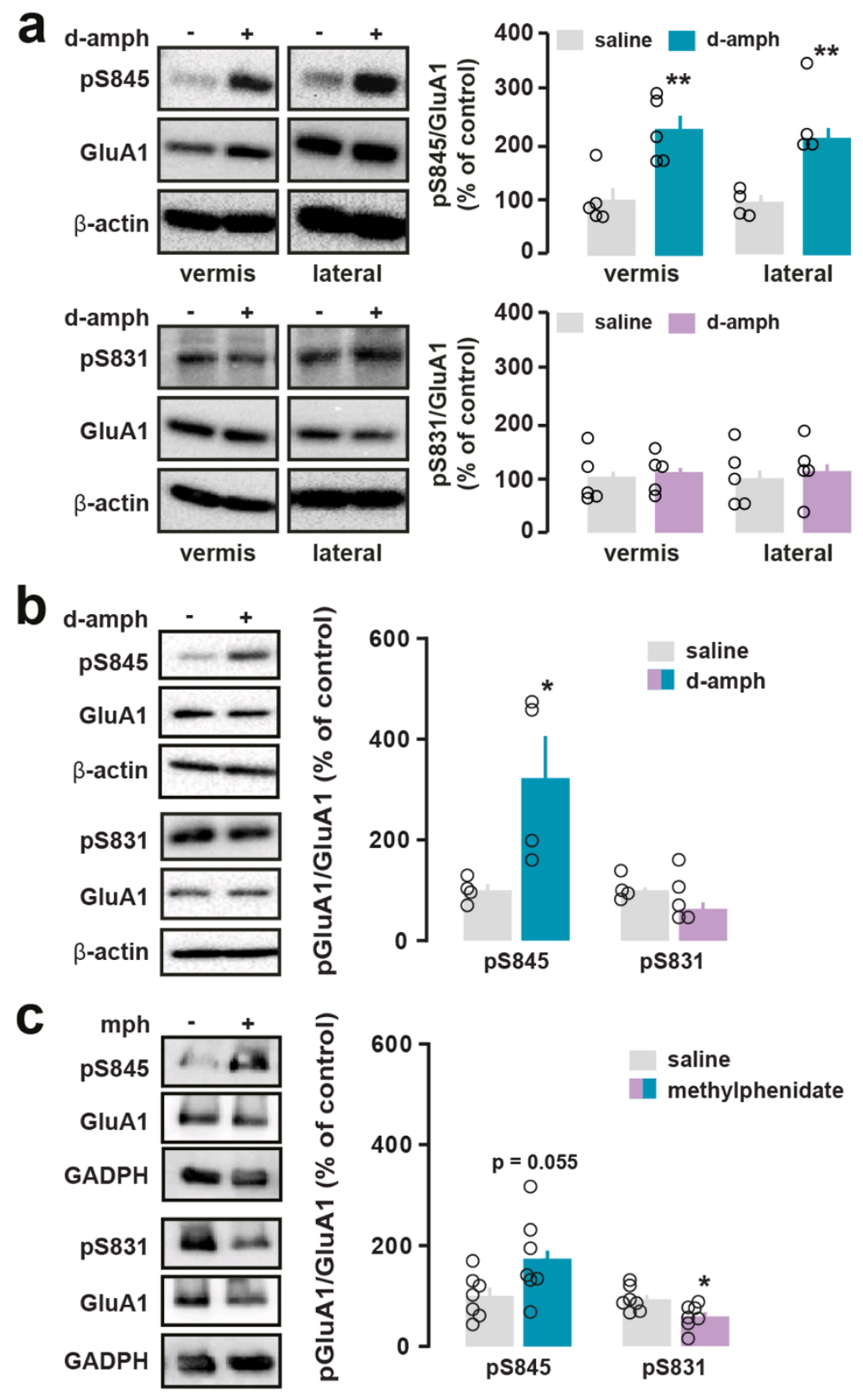




\section{Cutando et al., Figure 3}

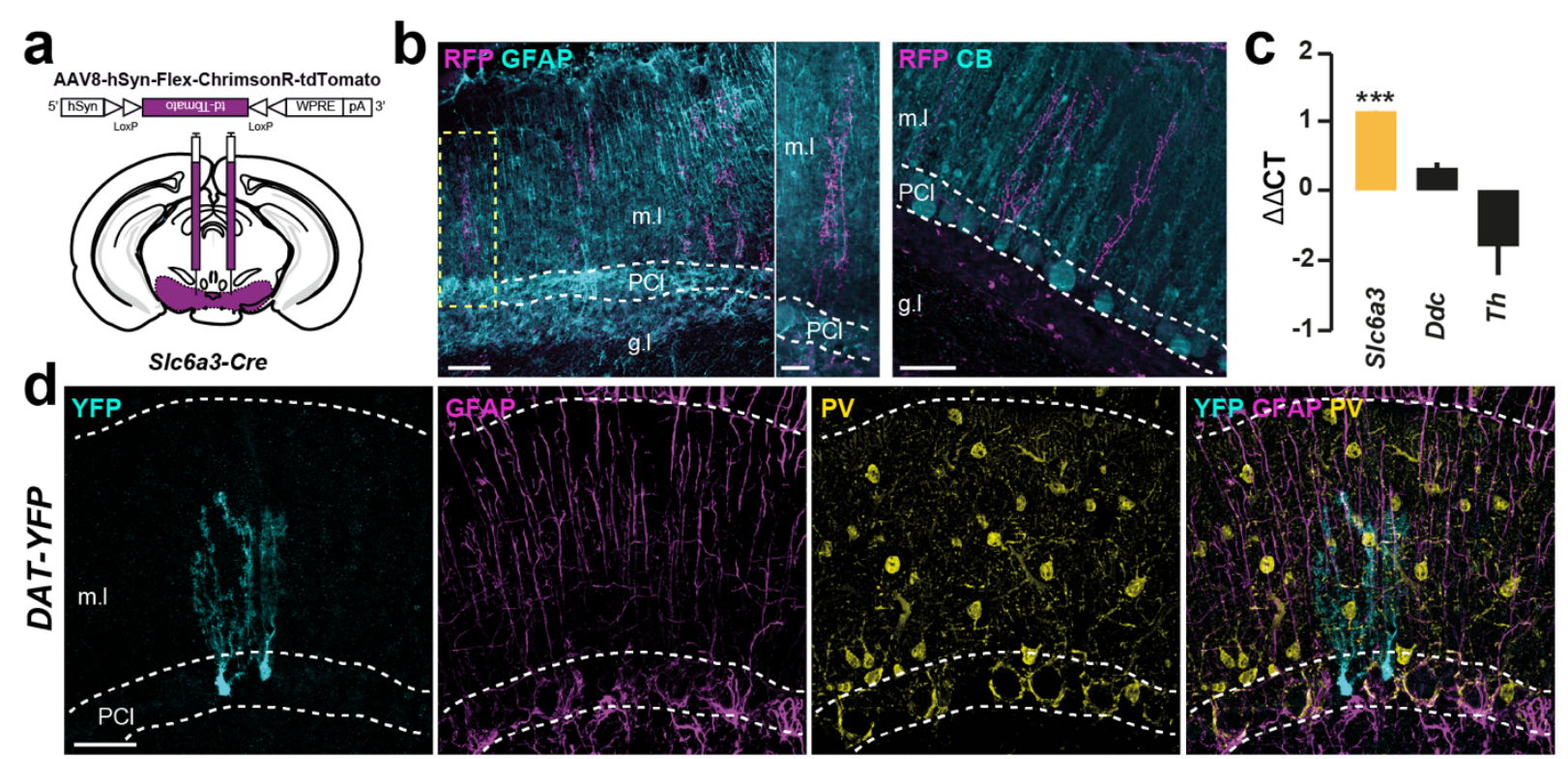




\section{Cutando et al., Figure 4}
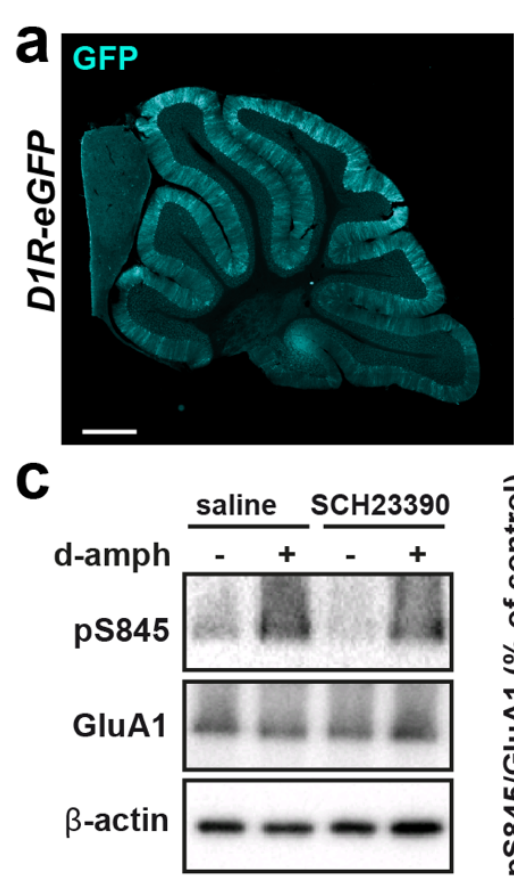
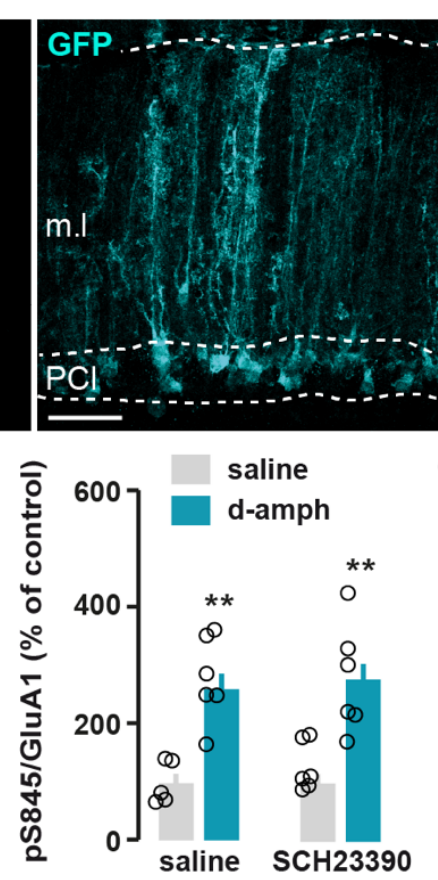

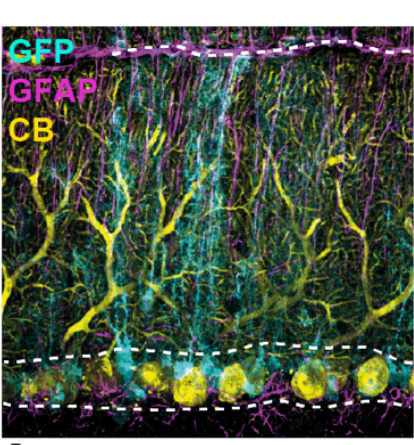

d
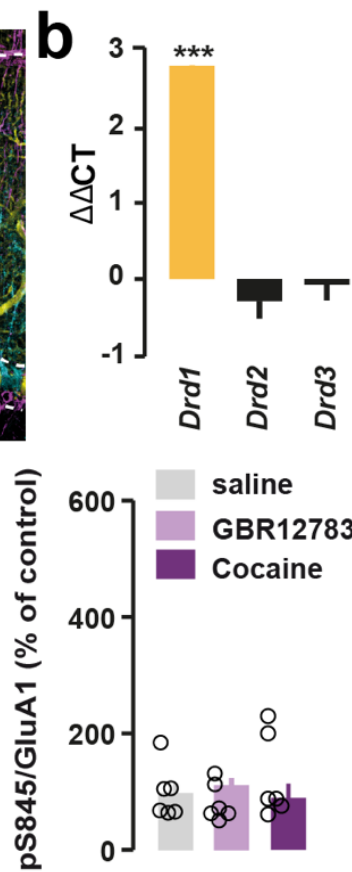


\section{Cutando et al., Figure 5}

a

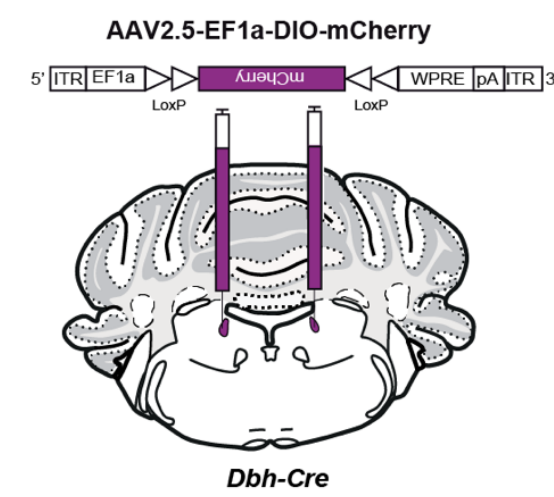

C mRnA expression (\% of control)

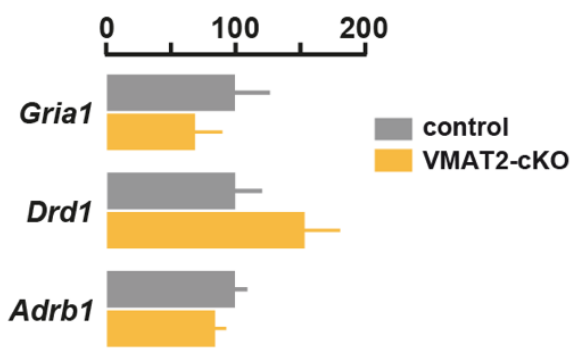

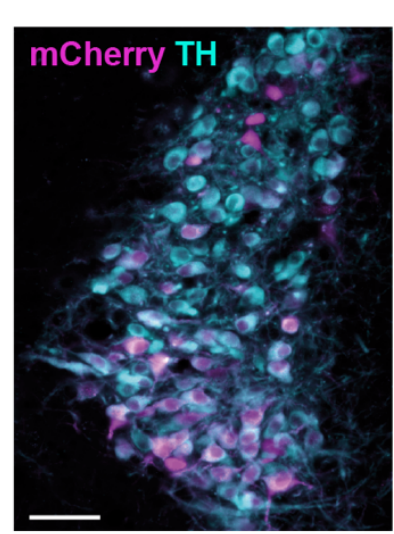

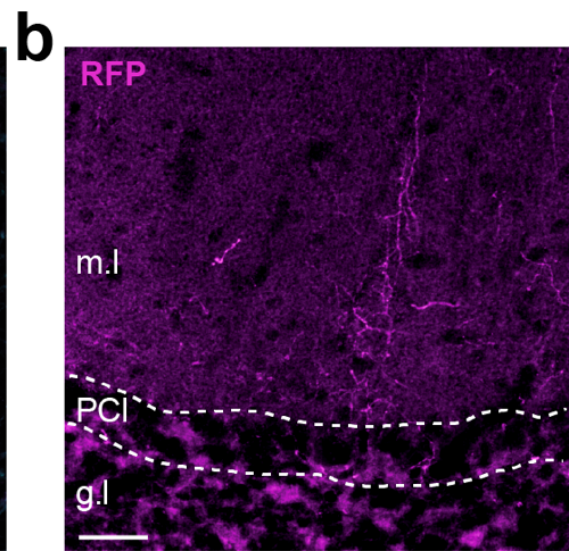

d

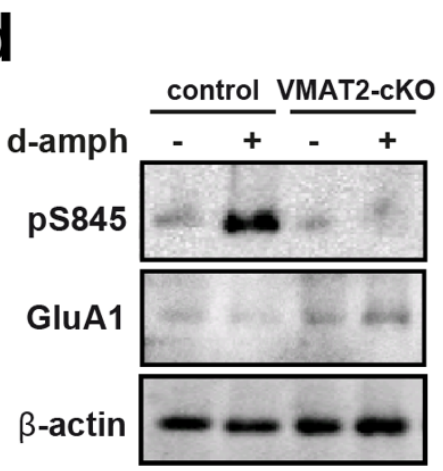

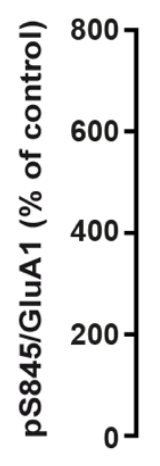

saline

d-amph

0

O Q $\begin{array}{llll}0 & 0 & 8 \\ 0 & 0 & 0 & 1 \\ 8 & 8 & 8\end{array}$ control VMAT2-cKO

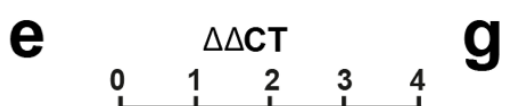

9

Adrb1 Adrb2

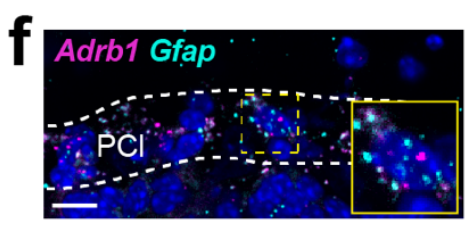

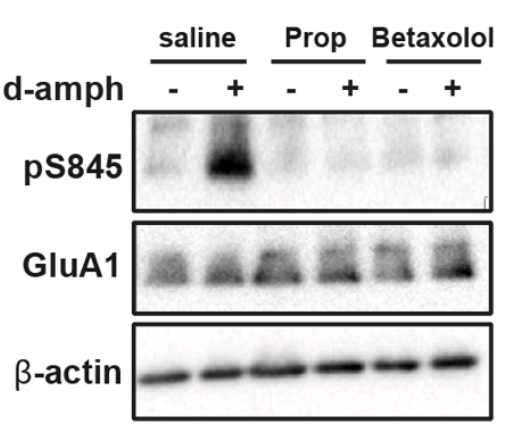

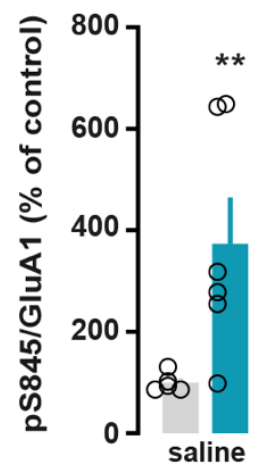

saline

d-amph

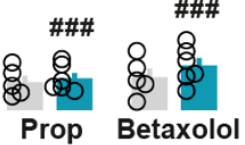




\section{Cutando et al., Figure 6}
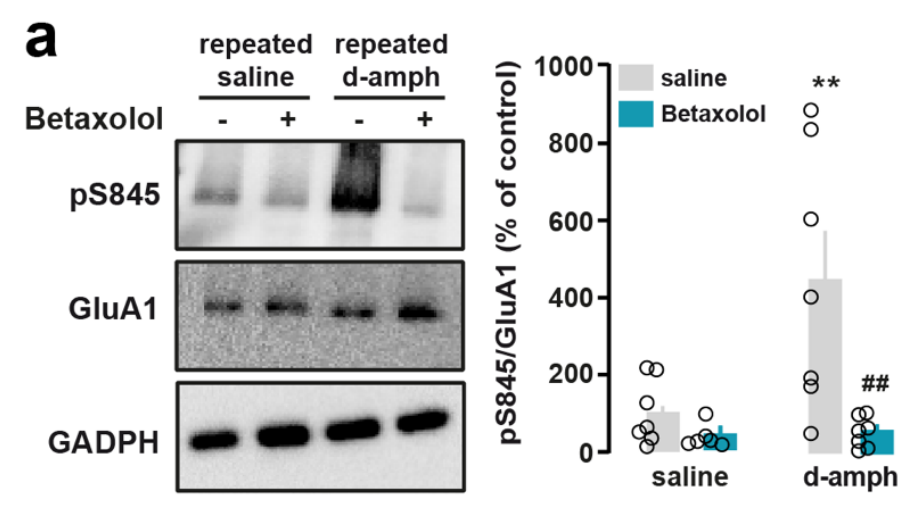

b
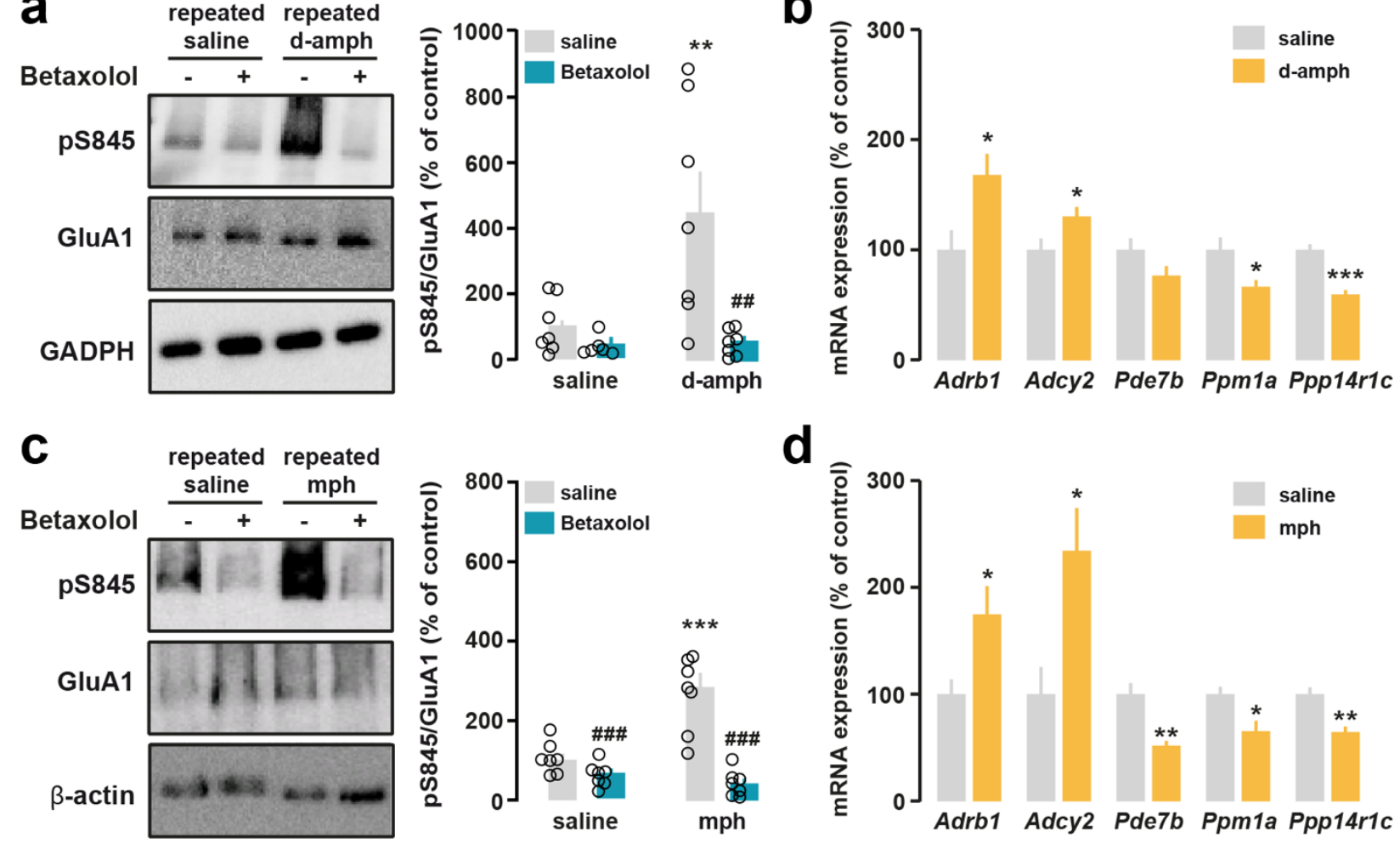

d

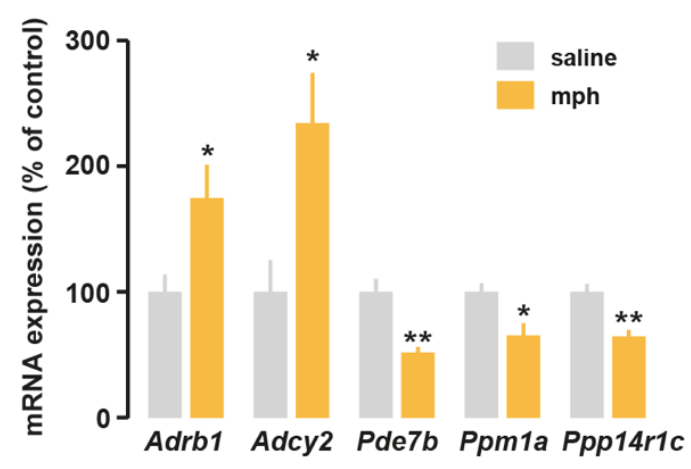




\section{Cutando et al., Supplemental Figure 1}

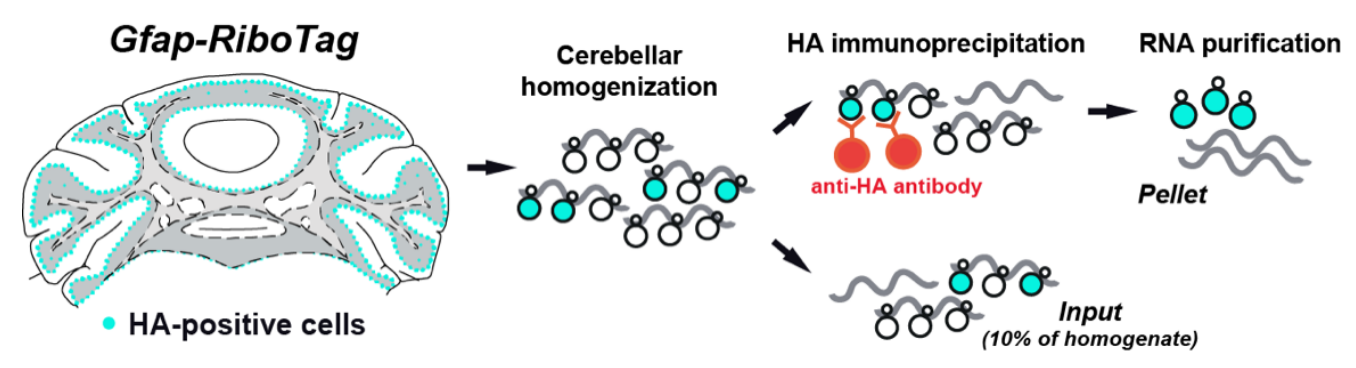




\section{Cutando et al., Supplemental Figure 2}

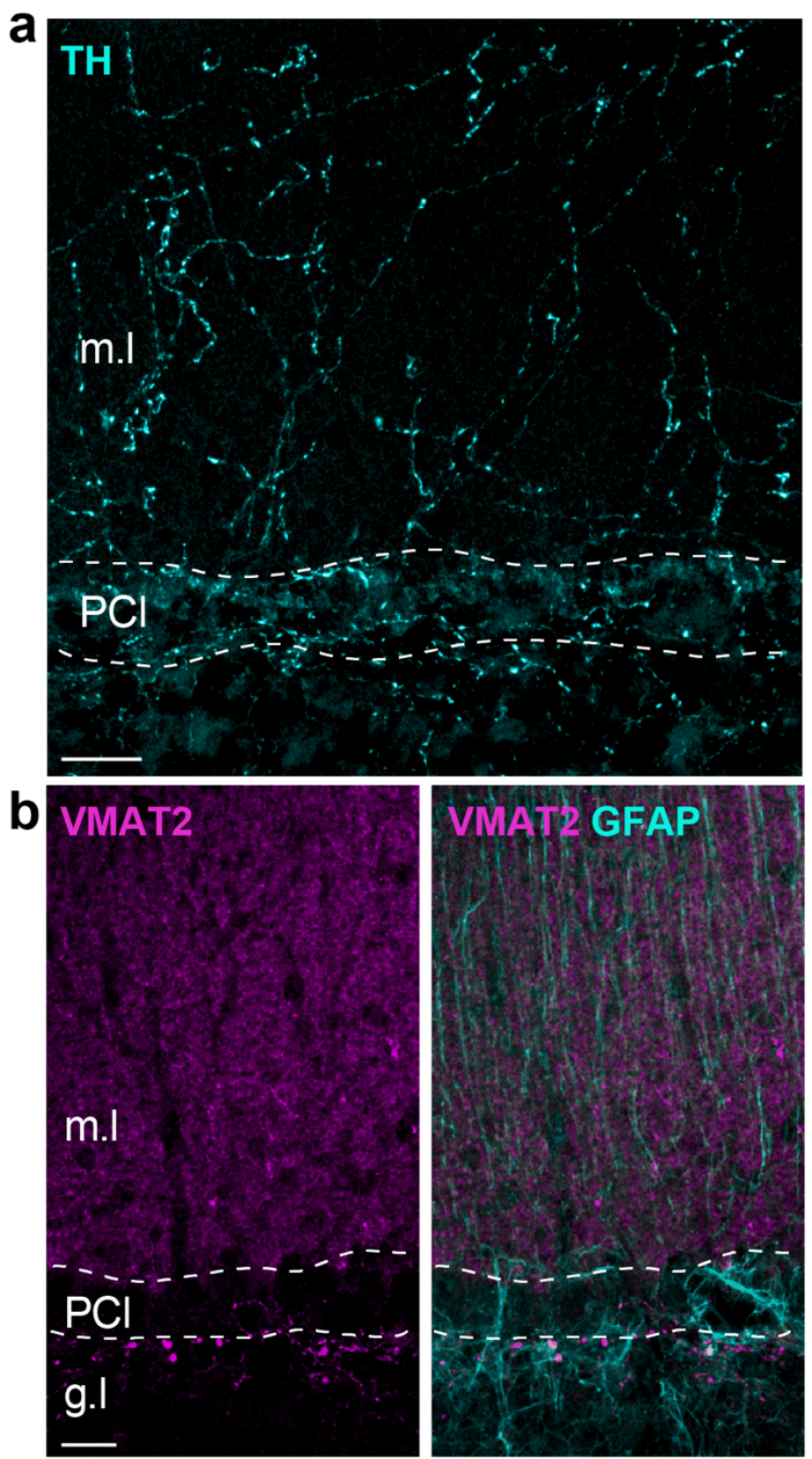




\section{Cutando et al., Supplemental Figure 3}

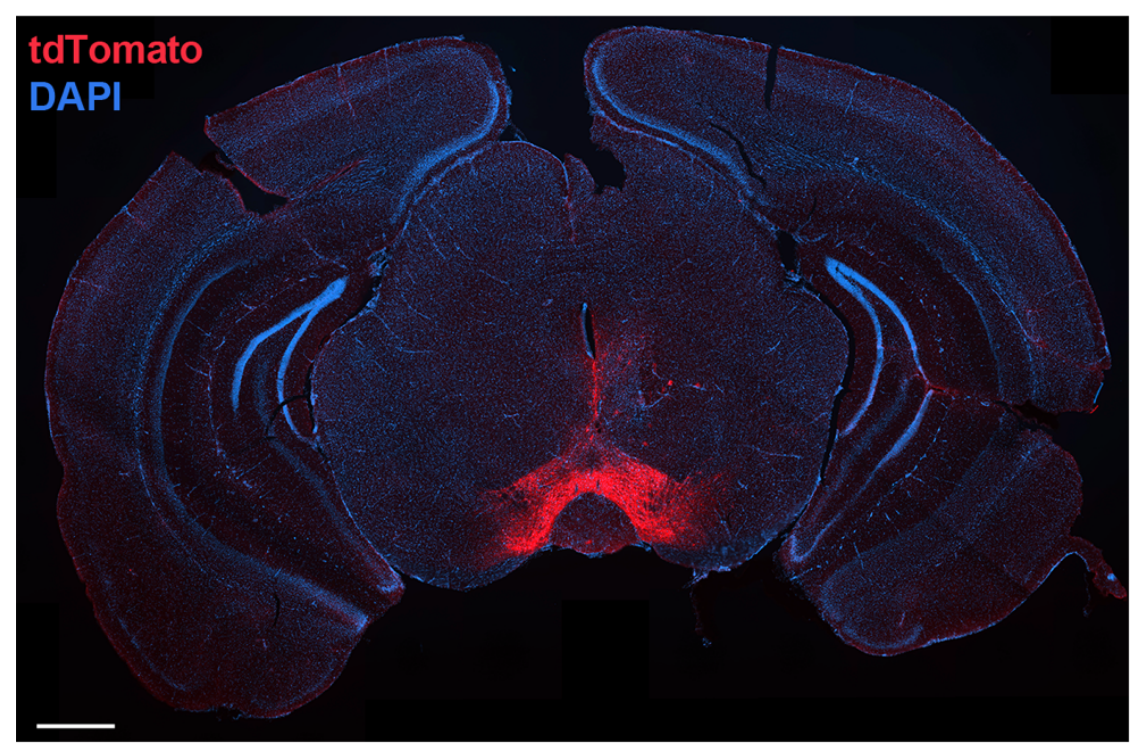




\section{Cutando et al., Supplemental Figure 4}
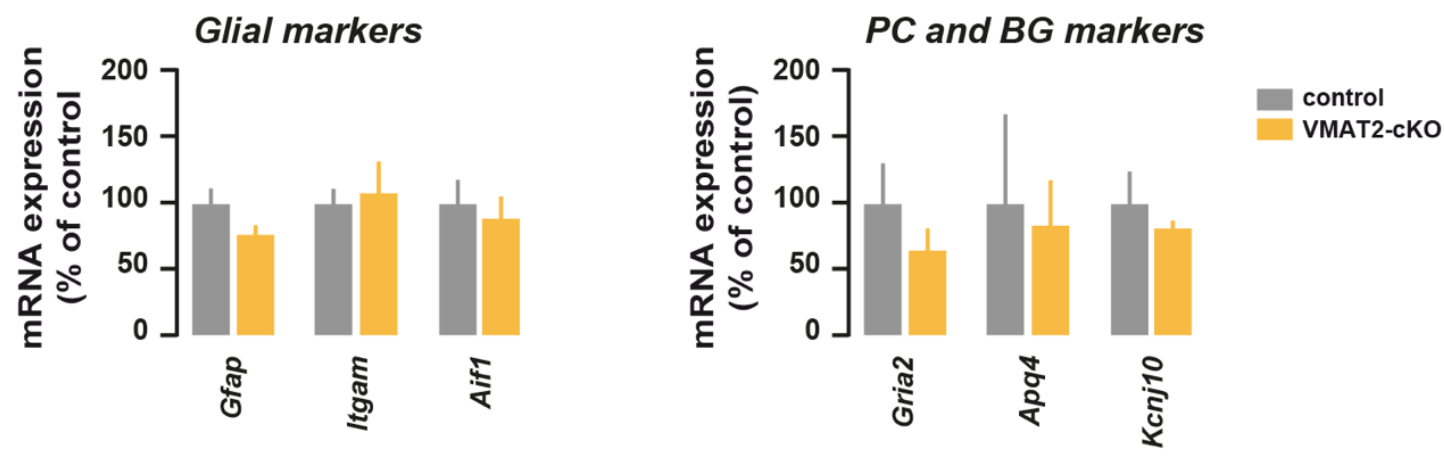

Catecholaminergic markers

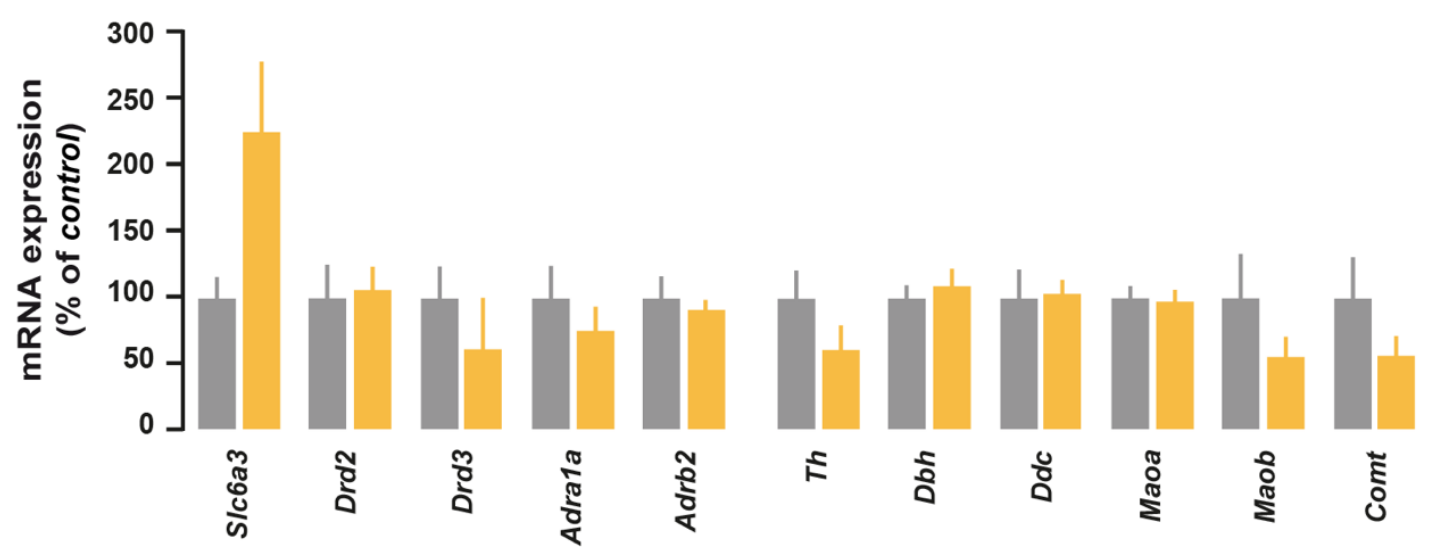




\section{Cutando et al., Supplemental Figure 5}

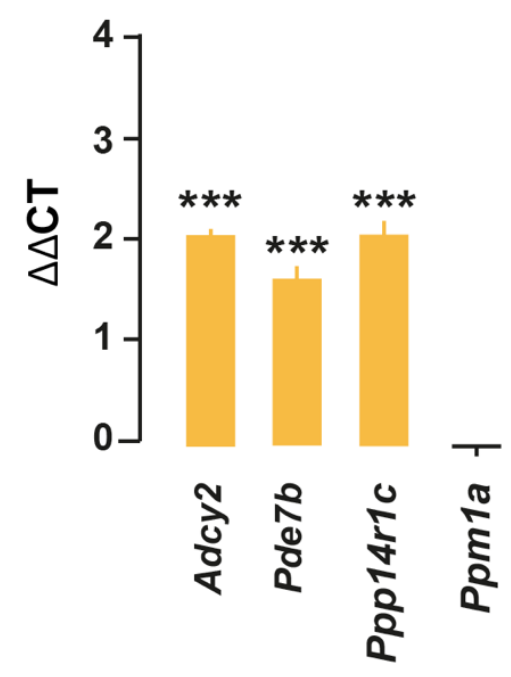

